\title{
Nanostructures for Biosensing, with a Brief Overview on Cancer Detection, IoT, and the Role of Machine Learning in Smart Biosensors
}

\author{
Aishwaryadev Banerjee ${ }^{1, *}$, Swagata Maity ${ }^{2}$ and Carlos H. Mastrangelo ${ }^{1, *}$ \\ 1 Department of Electrical \& Computer Engineering, University of Utah, Salt Lake City, UT 84112, USA \\ 2 Department of Condensed Matter Physics and Materials Sciences, \\ S.N. Bose National Centre for Basic Sciences, Kolkata 700106, India; maity.swagata94@gmail.com \\ * Correspondence: aishwaryadev.banerjee@utah.edu (A.B.); carlos.mastrangelo@utah.edu (C.H.M.)
}

Citation: Banerjee, A.; Maity, S.; Mastrangelo, C.H. Nanostructures for Biosensing, with a Brief Overview on Cancer Detection, IoT, and the Role of Machine Learning in Smart

Biosensors. Sensors 2021, 21, 1253.

https://doi.org/10.3390/s21041253

Academic Editor: José Miguel García

Received: 7 January 2021

Accepted: 7 February 2021

Published: 10 February 2021

Publisher's Note: MDPI stays neutral with regard to jurisdictional claims in published maps and institutional affiliations.

Copyright: (c) 2021 by the authors. Licensee MDPI, Basel, Switzerland. This article is an open access article distributed under the terms and conditions of the Creative Commons Attribution (CC BY) license (https:// creativecommons.org/licenses/by/ $4.0 /)$.

\begin{abstract}
Biosensors are essential tools which have been traditionally used to monitor environmental pollution and detect the presence of toxic elements and biohazardous bacteria or virus in organic matter and biomolecules for clinical diagnostics. In the last couple of decades, the scientific community has witnessed their widespread application in the fields of military, health care, industrial process control, environmental monitoring, food-quality control, and microbiology. Biosensor technology has greatly evolved from in vitro studies based on the biosensing ability of organic beings to the highly sophisticated world of nanofabrication-enabled miniaturized biosensors. The incorporation of nanotechnology in the vast field of biosensing has led to the development of novel sensors and sensing mechanisms, as well as an increase in the sensitivity and performance of the existing biosensors. Additionally, the nanoscale dimension further assists the development of sensors for rapid and simple detection in vivo as well as the ability to probe single biomolecules and obtain critical information for their detection and analysis. However, the major drawbacks of this include, but are not limited to, potential toxicities associated with the unavoidable release of nanoparticles into the environment, miniaturization-induced unreliability, lack of automation, and difficulty of integrating the nanostructured-based biosensors, as well as unreliable transduction signals from these devices. Although the field of biosensors is vast, we intend to explore various nanotechnology-enabled biosensors as part of this review article and provide a brief description of their fundamental working principles and potential applications. The article aims to provide the reader a holistic overview of different nanostructures which have been used for biosensing purposes along with some specific applications in the field of cancer detection and the Internet of things (IoT), as well as a brief overview of machine-learning-based biosensing.
\end{abstract}

Keywords: nanostructures; biosensor; cancer detection; machine learning

\section{Introduction}

The concept of biosensing is deeply embedded within most organic life forms, and from an evolutionary point of view, this has enabled them to survive harsh environments and predators. Common examples of this include augmented olfactory abilities of ca-nines, the electrosensitive nature of sharks, and toxin-sensing capabilities of certain algae [1-3]. According to the International Union of Pure and Applied Chemistry (IUPAC), a biosensor can be defined as "a device that uses specific biochemical reactions mediated by isolated enzymes, immune systems, tissues, organelles, or whole cells to detect chemical compounds usually by electrical, thermal, or optical signals" [4]. Figure 1 shows a schematic representation of the fundamental working principles of a biosensor. Clark and Lyons developed one of the first biosensors using an enzyme-electrode for glucose detection in the early 1960's [5]. Other examples of first and second generation of biosensors can be found here [6-9]. However, these sensors displayed limited ability for rapid sensing and discrimination of small 
amounts of toxic agents embedded within large amounts of a chemically inert but complex backgrounds. Following this, the scientific community witnessed a revolutionary era of micro-/nano-technology, which allowed us to explore hitherto unchartered territories and exploit the fundamentally novel features of nanoscale science and propel the field of biosensors to new heights.

Bioreceptor

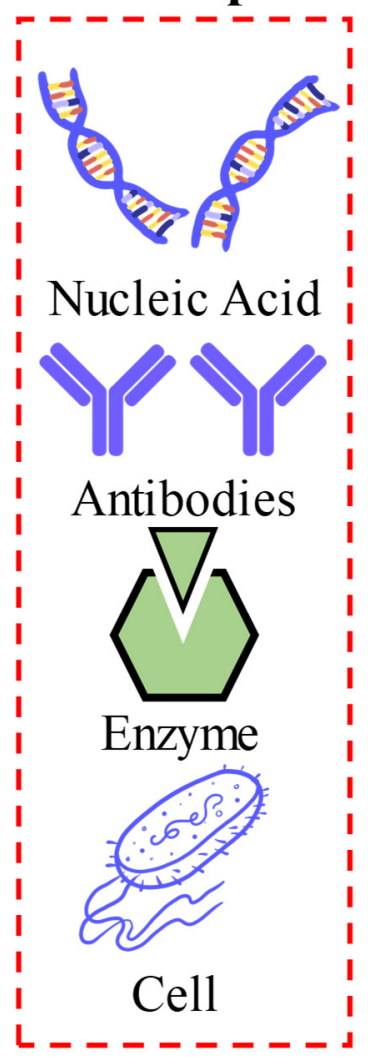

\section{Transduction}

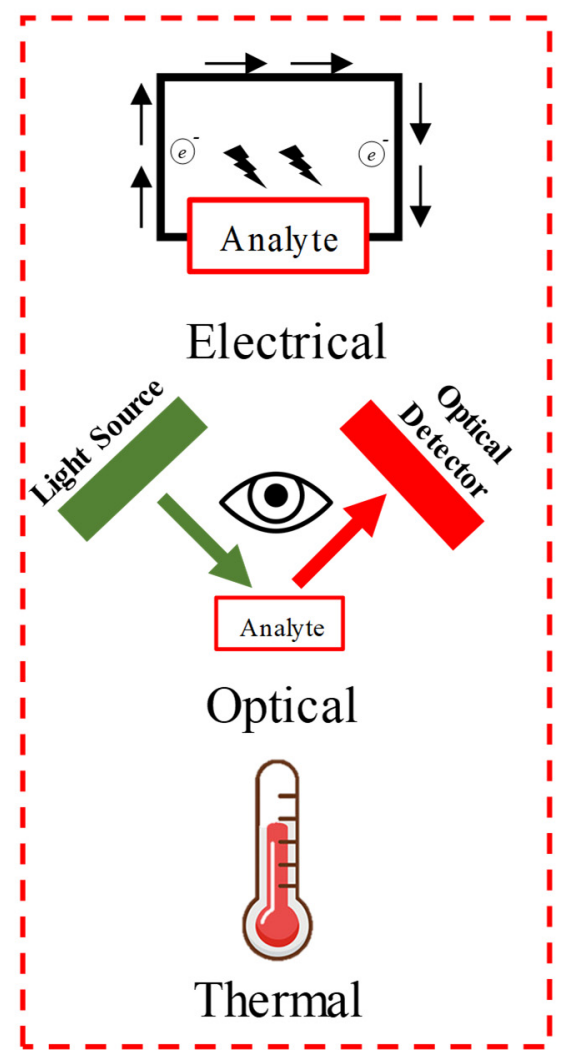

Figure 1. Schematic showing the working principle of biosensors based on different methods of transduction.

Advances in nanotechnology have allowed us to build structures or devices in the nanoregime, such as nanoparticles, nanotubes, nanorods and nanowires, which can directly probe and interact with the very biomolecules we intend to detect using biosensors. Such devices display unique properties, such as excellent electrical conductivity, tunable optical, electrical, and magnetic properties and show great promise for faster response and higher sensitivity at the device in comparison with conventional biosensors. Therefore, they can be exploited for a variety of bioengineering applications ranging from biosensors to drug delivery. Nanotechnology has had a significant impact on the field of disease detection, especially by using electrochemical, electromechanical, resonance, thermal, magnetic, and optical techniques. Nano-biosensors have advanced the ability to identify specific analytes and obtain detailed information regarding biomolecular profiles of various diseases. Accurate sensing and analysis of specific biomarkers has led to the development of advanced biosensor systems which are capable of sensing localized micro-environmental fluctuations, thus providing an indication of the disease, disease progression, and therapeutic assessment. However, in spite of their exciting properties, these nano-biosensors are plagued with certain disadvantages, such as drift, fouling, nonspecificity, and displaying irreproducible and nonuniform transduction signals.

There are a number of highly informative reviews in the literature which are an excellent resource for an in-depth understanding of certain specific nanostructures for biosensors [10-22]. However, this article aims at providing a holistic overview of the most 
widely used nanostructures for biosensing purposes and thereby presents the reader with a "big picture". It is structured in a manner similar to that of a textbook, with individual sections providing a complete review of a certain nanostructure, including sensor parameters and some recent examples from the literature. This allows the reader to form a simple yet broad understanding of the basic concepts and applications of commonly used nano-biosensors. Additionally, the article also explores the vital application of such biosensors in the field of cancer detection and the Internet of things (IoT). Cancer research, especially cancer detection, has always been a significant area of research which is continuously evolving and nano-biosensors provide a completely new dimension to this field of study. The article therefore provides an overview of nano-biosensors for cancer detection. Similarly, IoT is an emerging and a truly transformative technology which depends on a smart network of low-operating-power chemical/biosensors for successful implementation. Nanotechnology has enabled a practical realization of such sensors. Hence, the article also provides a discussion of the role of nanostructures in the successful implementation of this technology with a brief note on its future prospects. Finally, due to the exponentially growing influence of machine learning on multiple fields of research, this article includes a short review of machine-learning-based nano-biosensors.

The following sections of this review article will provide an overview of existing nano-biosensors along with their fundamental working principles and certain applications of such devices in varied biological fields. The article begins with a very brief discussion of various types of nano-biosensors and their applications. Following this, we provide a description and applications of thin-film-based biosensors. Next, a highly detailed description of nanostructure-based biosensors is also provided. In this section, we mainly describe sensors comprised of gold nanoparticles, carbon nanotubes, graphene, and quantum dots. A plethora of sensor applications is also discussed with literature references. After this, we provide a discussion of the impact nano-biosensors have had on the field of cancer research and low-power sensors for the Internet of things, including future prospects of this technology. Finally, a brief review of machine-learning-based biosensors is also provided to conclude the review.

\section{Nano-Biosensors: An Overview}

Nano-biosensors are a class of sensors which are used to observe, measure and analyze biological events using sensors which have been built using the techniques of nanotechnology. They are mostly built using various forms of quantum dots, nanoparticles, nanowires, and nanofilms. Most naturally occurring biological systems such as viruses, membranes, and protein complexes and their interactions take place in the nanometer regime. This makes devices whose dimensions are in the nanoscale ideal candidates for biomedical and bioanalytical applications to obtain higher degrees of sensitivity, specificity, and faster response times compared to the traditional methods of biosensing. These include a multitude of varied applications such as using amperometric nanodevices for enzymatic detection of glucose, quantum dots as fluorescence agents for the detection of binding, and even using bio-conjugated nanomaterials for specific biomolecular detection. For example, colloidal nanoparticles have been conjugated with antibodies for highly specific immunosensing purposes. Similarly, the electronic and optical properties of metal nanoparticles have been exploited for DNA/RNA detection and analysis. Nanomaterials/structures such as quantum dots, nanoparticles, and nanotubes are the key components of any nano-biosensor system. Based on these structures, devices such as nanosensors, nanoprobes and other miniaturized systems have revolutionized the field of chemical and biosensing. Such nanodevices have been specifically designed to exhibit high response times and ultralow power requirements. Nanomaterials such as metal nanoparticles, oxide nanoparticles, magnetic nanomaterials, carbon materials, quantum dots, and metallophthalocyanines have been used to improve the electrochemical signals of biocatalytic events that occur at the electrode/electrolyte interface. Functionalized nanoparticles that are bound to organic molecules have been developed for use in biosensors. The synthesis of such nanostructured 
materials and nanodevices involves a varied number of techniques, and the selection of a synthesis technique depends on the material of interest or the type of nanomaterial such as $0 \mathrm{D}, 1 \mathrm{D}, 2 \mathrm{D}$, their sizes, and the desired quantity [23-25]. For example, physical techniques such as high-energy ball mixing/melt mixing, physical vapor deposition (PVD), laser ablation, electric arc, and sputtering have been extensively used to develop nanostructured materials for biosensing purposes. Chemical methods of synthesizing nanostructures, such as the sol-gel process and inverse micelles formation have also been widely used. Bottomup and top-down are the main approaches for synthesis of nanostructures materials. In the bottom-up technique, the miniaturization of material constituents followed by selfassembly results in the creation of nanostructures. Such methods have been widely used for the formation of quantum dots and nanoparticles from colloidal dispersions. These techniques are preferred on account of lesser defects and a more homogenous chemical composition. Contrary to this, top-down approaches involve extremely controlled processing of macroscopic structures which can be carefully engineered to build the desired nanostructure. Examples of this include Inductively Coupled Plasma (ICP) etching techniques, ball milling, and severe plastic deformation. However, a major drawback of these methods is the presence of significantly large quantities of imperfections in the surface structure. Nanomaterial such as carbon nanotubes (CNTs), graphene, quantum dots (QDs), nanoparticles (NPs), and nanocomposites, have been widely investigated by the research community and used for diagnostics and biosensors in the last decade. However, the advancement of such technologies has also posed certain uncomfortable questions, for example those related to the safety of various nanomaterials, which need to be answered and addressed before a majority of these technologies can be made available for pedestrian use [26]. As shown in Figure 2, there are numerous fields of research which can be pursued while studying nano-biosensors. However, we will be focusing mainly on the fabrication, materials, characterization, and direct applications of nanotechnology enabled biosensors.

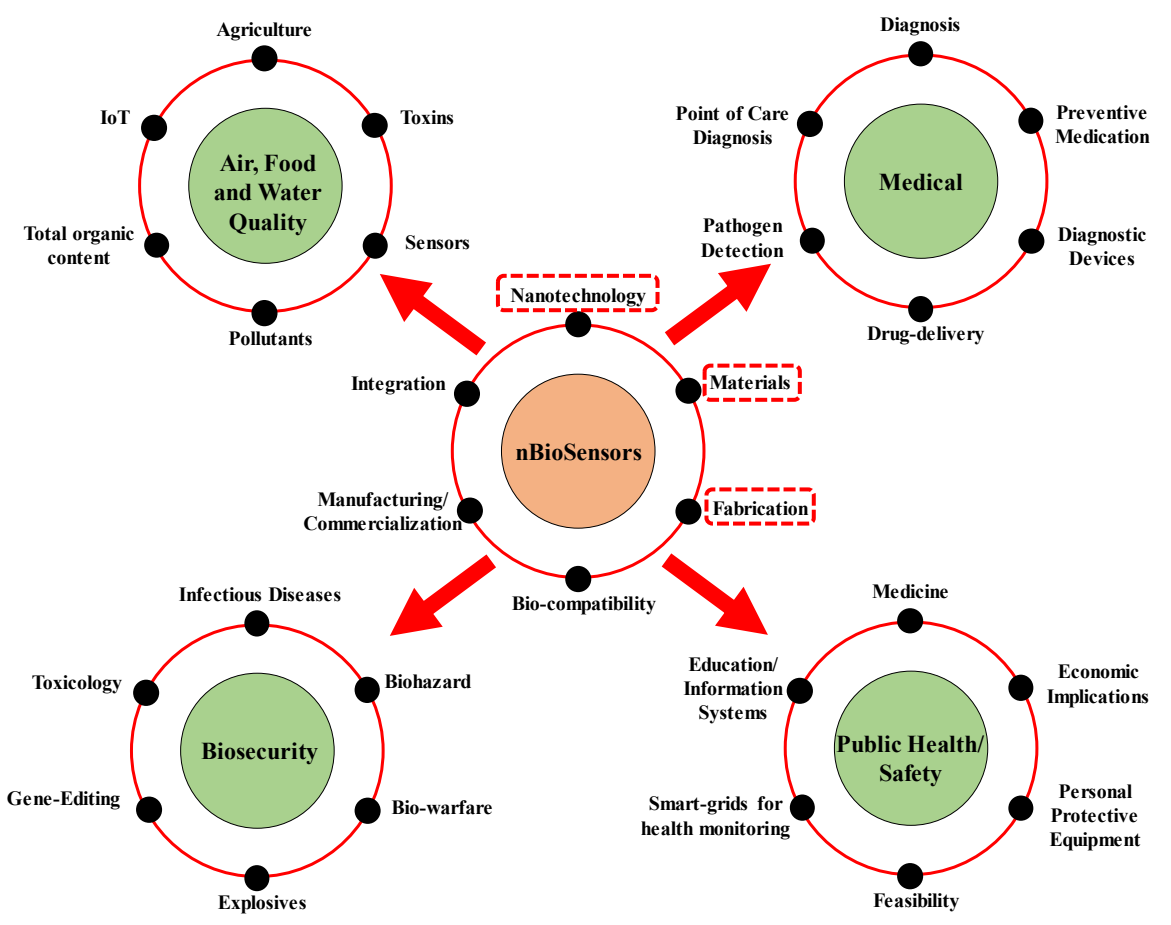

Figure 2. The field of research dealing with advancement in nano-biosensors is vast and comprises of a variety of multidisciplinary aspects. The primary applications of nano-biosensors can be broadly divided into the following fields: monitoring of air, food, and water quality, medical research, biosecurity, and public health and safety. These fields of research can be further subdivided into categories. 
For example, research dealing with air monitoring comprises of studies and advancements in sensor technology, which can be utilized for detecting levels of carcinogenic VOCs and other air pollutants. Similarly, research in point-of-care diagnosis have been fundamental in propelling advancements in the field of medical research. Additionally, development of more advanced PPEs have been crucial in the fight against infectious diseases, such as the ongoing COVID-19 pandemic. Therefore, one must appreciate the sheer vastness of the field of nano-biosensors. As highlighted in the figure, we aim at providing a broad description of certain aspects of nano-biosensors, including the concepts of nanoscale science which is fundamental to the realization of such biosensors and the materials which have been widely used to fabricate such nanodevices, along with numerous examples from the literature.

\section{Thin-Film-Based Biosensors}

The working principle of thin-film-based biosensors is based on the selective adsorption of analyte molecules on a functionalized thin film. These biosensors act as physicochemical (optical, mechanical, magnetic, or electrical) transducers, which convert the signal resulting from the recognition of the biological analyte into another form of a measurable signal. A plethora of thin-film-based biosensors can be found in literature references. These are comprised of complex structures of thin films, which give enormous functionalities to the sensors. The thin films are made from either organic and/or inorganic materials, such as metals, glass, polymers, silicon, or metal oxides. Specific structures of biological molecules can also be used as thin films. The most crucial part of such biosensors is the analyte-sensitive layer, i.e., the layer which reacts to the biomolecule. On this surface, atomic interactions and surface free energies and forces are different from the bulk of the material, and the analyte-specific reaction starts here. Surface activation can be necessary to immobilize biological analytes on sensitive layer. For this purpose, self-assembled monolayers (SAM)-enabled surface-modification techniques are the most widely used [27]. Thin films can be used to functionalize (e.g., control hydrophobicity, bio-affinity, biocompatibility, and electrical activity) the surface of biosensors with or without using surface-treatment processes. For example, Parylene $\mathrm{C}$, which is a polymer commonly used in the packaging of integrated circuits, is a hydrophobic polymer with a water contact angle of $87^{\circ}$, and its surface can be made hydrophilic with oxygen-plasma treatment, which allows the realization of a plethora of microfabricated, microfluidic devices that function on the basis of efficient capillary flow. Other examples of similar biocompatible thin films include dielectric coatings such as $\mathrm{SiO}_{2}, \mathrm{TiO}_{2}, \mathrm{Al}_{2} \mathrm{O}_{3}$, and $\mathrm{Si}_{3} \mathrm{~N}_{4}$. These layers are crucial to the practical deployment of thin-film-based biosensors and drug delivery systems. Such layers are often exploited for their superior electrical, optical, magnetic, and mechanical properties in comparison with their bulk counterparts. For example, Sokolov et al. demonstrated that a PDMS thin-film utilized as a miniature pressure sensor displayed a recovery time which was $~ 50$ times faster than a pressure sensor which comprised of a bulk PDMS layer [28]. The most commonly used polymers for biosensing purposes include PDMS, parylene-C, perfluoropolyether, polyetheretherketone, polypropylene, and polystyrene. Besides dielectrics, metallic thin films are widely used in biosensors to form either bond pads for electrical probing of the analyte or as activation surfaces for appropriate functionalization. The most widely used metal for biosensors is gold due to it being biocompatible, a noble metal, and its excellent electrical properties. Functionalization of Au with self-assembled thiol molecules is the most common technique for activating the gold surface. Additionally, a thin layer of metal is often deposited for improving adhesion between two layers which are naturally incompatible. Metals such as $\mathrm{Cr}$ and Ti have been widely used to improve adhesion between the electrically active layers (such as $\mathrm{Au}$ ) and the underlying $\mathrm{Si} / \mathrm{SiO}_{2}$ substrates. Functionalization using organic thin films is an equally important aspect of thin-film-based biosensor technology. The functionalization process essentially consists of depositing a thin layer of organic films such as a variety of thiol molecules, proteins, and nucleic-acid molecules. The selection of the appropriate surface chemistry is crucial to the uniform formation of the organic films and depends on the specific material to be activated. Silane molecules are often used to functionalize inorganic surfaces, 
such as glass. Numerous examples of similar functionalization techniques can be found in these literature references. Figure 3 shows the schematic of the working principle of thin-film-based biosensors.

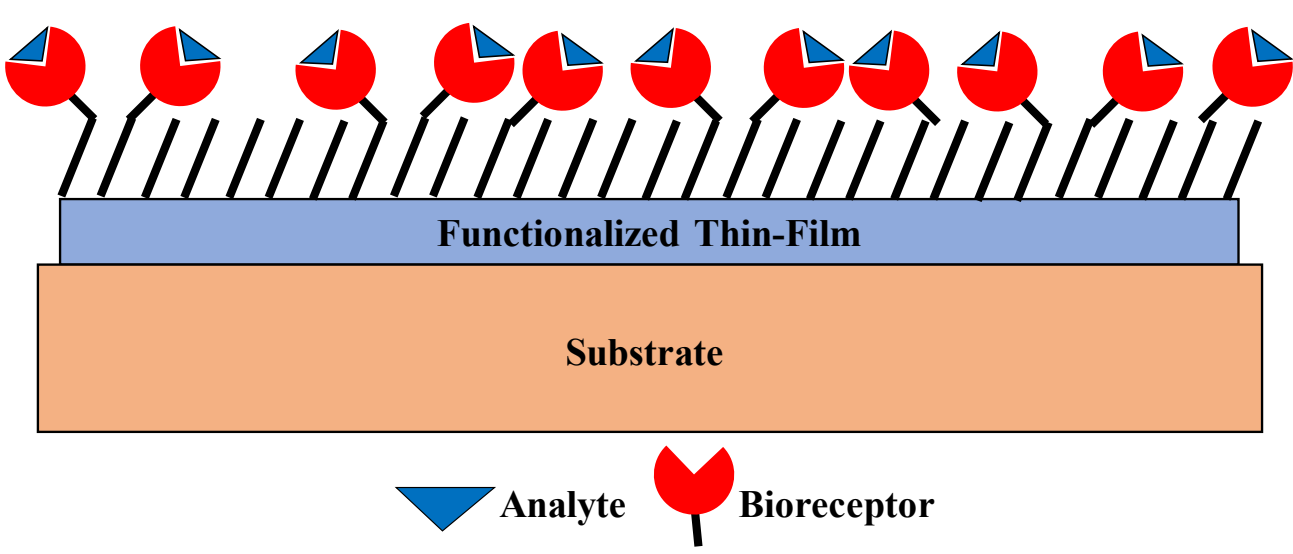

Figure 3. Working principle of thin-film-based biosensors. The thin films are functionalized with appropriate bioreceptors to realize specific capture of analyte molecules. This capture is then measured to indirectly quantify the analyte concentration.

\section{Thin-Film Biosensors}

Nanostructures are attractive options for biosensor applications due to their observable quantum effects and large surface area. Exploiting these unique properties potentially enables us to design biosensors with improved characteristics compared to their traditional counterparts. Essentially, such nanostructures can be realized in 0D (for example, quantum dots or nanoparticles), $1 \mathrm{D}$ (for example, nanowires or carbon nanotubes) or 2D (for example, graphene). The following sections will provide a broad overview of the most widely used nanostructures for biosensing purposes.

\subsection{Gold Nanoparticles}

The recent advances in nanotechnology have allowed for cheap and rapid synthesis of nanoparticles (NPs), and these NPs have demonstrated augmented sensitivity against certain analytes and have therefore been extensively used for biosensing purposes. For example, metallic NPs such as gold and silver nanoparticles, dielectric NPs such as $\mathrm{SiO}_{2}$ or $\mathrm{MnO}_{2}$ nanoparticles, polymeric NPs, and semiconductor NPs such as CdS nanoparticles have been integrated with microstructures for efficient and sensitive biosensing [29-35]. Owing to their varying electrical characteristics, these different categories of NPs are suitable for varied roles in different biosensing systems. For example, metallic NPs are generally used for electrical probing of biomolecules. Dielectric NPs have been often employed to immobilize biomolecules and semiconductor nanoparticles have been traditionally used as labels or biomarkers. Amongst a plethora of nanoparticles which are currently used for biosensing, gold NPs (AuNPs) are the most widely used as the analyte-sensitive layer for biosensor applications due to their biocompatibility, unique opto-electronic properties, and their relatively simple fabrication and modification techniques. The size of chemically synthesized AuNPs typically lie in the range of 1-100 nm, and these NPs have a high surface-to-volume ratio. AuNPs have a much higher surface energy than most other NPs and therefore are used to immobilize a wide variety of biomolecules. Due to its excellent conductive properties, AuNPs can promote very fast and direct electron transfer between a wide range of electroactive species and electrode materials. Furthermore, useful characteristics of AuNPs such as light-scattering properties and large enhancement ability of local EM fields can be used as signal amplification tags. In a nutshell, all these unique properties of AuNPs have been exploited to enhance the performance of optical, electrochemical, and piezo-electric biosensors. Figure 4 shows a schematic representation of the working 
principle of AuNP-based biosensor. The following sections briefly describe the application of AuNPs in the fields of these biosensors with relevant examples.

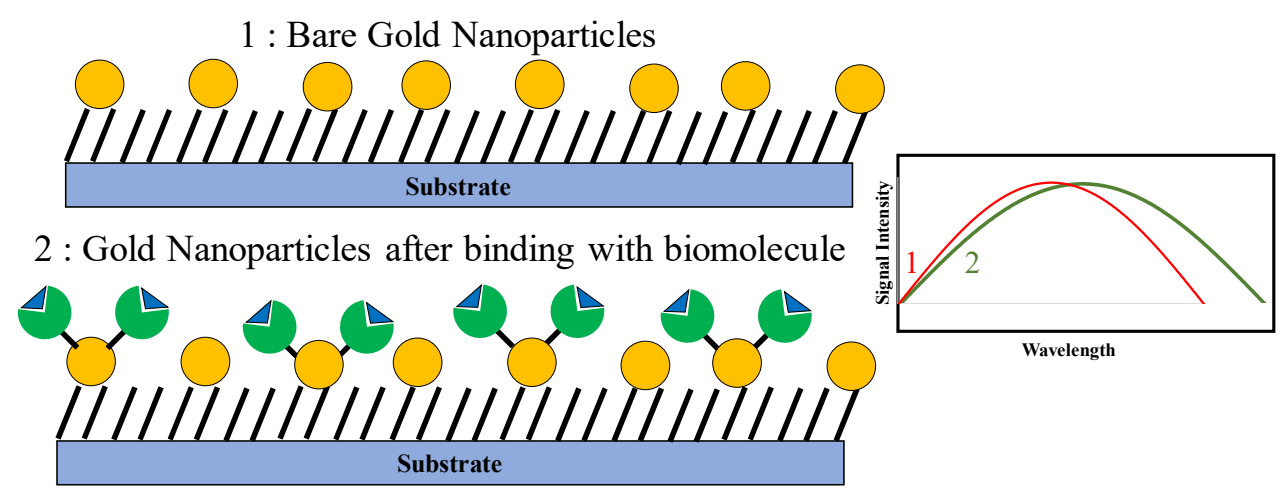

Figure 4. Gold nanoparticle (AuNP)-based biosensors. Functionalized AuNPs aid in the capture of analyte molecules. The electrical/optical properties of AuNPs are utilized to obtain enhanced signals which are proportional to the analyte concentration.

AuNP-based optical biosensors: As the name suggests, these devices are designed to realize a measurable transduction between the presence or change in concentration of the analyte of interest and the optical properties of the biosensor. The fundamental principle behind gold nanoparticle assisted biosensing is the collective oscillation of plasmons in response to incident electromagnetic (EM) waves. An example of such a phenomenon is surface plasmon resonance (SPR), where the interaction between the incident EM waves and the conduction-band electrons of $\mathrm{Au}$ is used for probing surface characteristics of the same. This interaction results in the resonant coherent oscillations of the surface conduction electrons of the metal, and the characteristics of these oscillations is a function of the concentration of the analyte of interest, which is present on the surface. Generally, the specific binding of biomolecules on the surface of metals results in a change of the dielectric constant of the surrounding medium, which then causes a change in optical characteristics of any EM wave which is incident on the metallic surface. This change is proportional to the concentration of the coated biomolecules, and therefore, accurate measurements of the reflected EM wave provide relevant information regarding the concentration of the analyte of interest. Englebienne was one of the first researchers to report a red-shift in the SPR resonant frequency of gold particles coated by a monoclonal antibody [36]. For the last two decades, significant efforts have been made to correlate the plasmon-absorbance characteristics of AuNPs with the refractive index of the surrounding medium (which in turn depends on the concentration of the coated biomolecule). The most significant advantage of AuNPs in comparison with traditional metallic thin-film devices is that AuNP-based sensors display augmented SPR signals which result in higher sensitivity of the biosensor and accuracy of measurement as well as a lower limit of detection.

Some significant examples include the work of Lin et al. who used the SPR technique and demonstrated an optical-fiber-based biosensor, sensitive to organophosphorous pesticides [37]. The presence of the pesticide led to an increase in the local refractive index which led to a change in the attenuation of the incident light. Therefore, measuring the attenuation of the light could easily determine the concentration of the pesticide. The presence of AuNPs significantly improved the sensitivity of the biosensor. Using similar principles, He et al. used AuNPs for specific detection of DNA hybridization [38]. Generally, the literature suggests that an increase in sensitivity of about 2-3 orders of magnitude is observed due to the presence of AuNPs as compared to other unamplified biosensing techniques. Li et al. performed SPR imaging to analyze single-nucleotide polymorphisms in genomic DNA [39]. The common underlying principle in the aforementioned examples is of AuNP-assisted signal amplification. This amplification is essentially the result of electronic coupling between the localized surface plasmon of AuNPs and the propagating 
plasmon on the SPR gold surface and the increase of effective mass of the immobilized analytes, due to the high density and high molecular weight of AuNPs. Additional examples of AuNP-based amplified biosensors include the contributions of Okamoto, Matsui, and Qi [40-42]. Furthermore, AuNPs have also been integrated with other photonic structures. For example, Tseng et al. developed an immunosensor based on AuNPs integrated with an optical fiber and conjugated with recognition proteins, where the shift in interference fringe was proportional to the analyte concentration [43]. Finally, AuNPs have also been used for surface enhanced Raman scattering techniques. For example, Cao et al. demonstrated sensitive detection of oligonucleotide targets by functionalizing oligonucleotides and Raman-active dyes on AuNPs [44].

AuNP-based electrochemical biosensors: Electrochemical biosensors are devices which are designed specifically for transduction of biochemical signals into measurable electrical signals. These sensors have been widely investigated in the last couple of decades due to their relatively simple fabrication process and low-cost detection capabilities. As mentioned above, the excellent electrical properties, biocompatibility, and catalytic properties of AuNPs make them an attractive component of electrochemical sensors. Integrating AuNPs with existing electrochemical sensors leads to enhanced transduction signals due to an "amplified" electrode surface and augmented electron transfer between redox centers in proteins. AuNPs have also been used as catalysts for electrochemical reactions. The role of AuNPs can be broadly classified as (1) electron transfer mediators and (2) immobilization platforms.

Usually, the active center of most biomolecules (for example a protein) is surrounded by a thick layer of electrically nonconducting shells, which impedes the flow of electrons between the electrically active center and the probing electrode, which leads to a poor output electrical signal. Natan et al. demonstrated for the first time, the amplification of electrical signals due to augmented electron transfer between the active center and the electrode [45]. Similarly, Willner et al. studied the electronic properties of AuNP coated with glucose oxidase [29]. The enzyme-coated electrodes displayed fast electron transfer between the redox center of the protein and the AuNPs. AuNPs have also been integrated with polymer-based electrochemical biosensors. Such biosensors which employ AuNP dispersed in various polymers have exhibited augmented stability and reusability. For example, $\mathrm{Xu}$ et al. have demonstrated biosensing properties of a composite material comprising of AuNPs dispersed in carboxymethyl chitosan for hydrogen peroxide sensing using electrochemical methods [46]. Ju et al. built a disposable immunosensor, capable of multi-analyte testing, which included four different horseradish peroxidase-labeled antibodies immobilized on AuNPs on screen-printed carbon electrodes with chitosan sol gel [47].

AuNPs are ideal for immobilizing biomolecules, in contrast to their bulk counterparts, since biomolecule adsorption on bulk materials has often led to degradation of their properties. For example, adsorption of protein biomolecules on the surface of bulk materials has often led to denaturation. Adsorption of such bio-molecules on AuNP surfaces has shown no signs of degradation due to the biocompatibility and high surface energy of gold. Additionally, due to their inherently higher surface area than their bulk counterparts, AuNPs can immobilize a far greater number of protein molecules, which therefore allows the realization of more sensitive biosensor devices. For example, Andreescu et al. utilized immobilized periplasmic glucose receptors on AuNPs and measured their electrical properties as a function of glucose concentration to develop a novel glucose sensor [48]. Similarly, based on this principle of biomolecule immobilization on AuNPs, many devices have been developed for sensitive and selective biosensing. Another vital application of this principle can be found in electrochemical DNA sensors which involve oligonucleotides immobilized on AuNPs. For example, using thiol end-groups, oligonucleotides have been immobilized on AuNPs by Kang et al. [49]. Specifically, the thiol end-group-modified oligonucleotides at the $5^{\prime}$ phosphate end were immobilized on the AuNPs and due to the high surface-to-volume ratio, the hybridization amount of DNA was greatly enhanced and 
therefore easily detected. A similar technique of biosensing was employed by Fang et al., where they immobilized oligonucleotides with a thiol group at the $5^{\prime}$-phosphate end on AuNPs, which were later self-assembled on cystamine-modified Au electrodes for detecting DNA hybridization [50].

In addition to the above-mentioned applications, AuNPs have been used in conjugation with other nanostructures such as carbon nanotubes (CNTs) and graphene to further enhance their immobilization and binding capabilities. For example, Cui et al. have built an electrochemical biosensor based on the conjugation of AuNPs and CNTs [51].

Although gold is an inert element, small-sized AuNPs have demonstrated their ability to act as a catalyst. This property of AuNPs has been widely exploited for biosensing purposes. Such properties of AuNPs are generally believed to be a result of quantummechanical effects arising due to their much augmented surface-to-volume ratio. AuNPs have therefore been effectively utilized to reduce overpotentials of crucial electrochemical reactions as well as engineer the reversibility of certain redox reactions. For example, Tuener et al. demonstrated that $1.4 \mathrm{~nm}$-sized AuNPs provided catalyst-like features for oxidation of styrene by dioxygen [52]. Furthermore, as the AuNP size increased to $\sim 2 \mathrm{~nm}$, the nanoparticles are no longer effective catalysts. Similarly, Raj et al. investigated into the catalytic properties of AuNPs by demonstrating their role in the enhanced oxidation of NADH [53]. As an application of the catalytic property of small-sized AuNPs, Bharati et al. developed a glucose biosensor based on the AuNP-mediated redox reactions of $\mathrm{H}_{2} \mathrm{O}_{2}$ [54]. Another similar example involves biosensors utilizing the catalytic properties of AuNPs and developing an enzyme-free glucose sensor by immobilizing AuNPs inside a sol gel and on an electrode surface. Other properties of AuNPs which are exploited for the purpose of electrochemical biosensing include the ability of these nanoparticles to stabilize the biomolecules they are interacting with whilst not degrading their properties and simultaneously enhancing the stability of the biosensing devices.

AuNP-based piezoelectric biosensors: The final category of AuNP-based biosensors which will be explored in this article are AuNP-based piezoelectric biosensors. In these sensors, any mass changes initiated due to biological events are detected by the quartz crystal microbalance (QCM) method, which is based on the piezoelectric effect. Highdensity AuNPs with enhanced surface-to-volume ratios are integrated with piezoelectric biosensors to amplify the inherently weak signals. For example, Jiang et al. demonstrated a microgravimetric DNA biosensor integrated with AuNPs [55]. In this device, AuNPs functionalized with oligonucleotide probes were immobilized on the surface of the QCM. Hybridization with the probes led to a change in mass, which was detected by the QCM. Similarly, Li et al. also developed a DNA-hybridization piezoelectric biosensor [56]. Other examples of highly sensitive piezoelectric biosensors based on similar principles include the role of AuNPs as signal-amplification tags for detecting DNA mutation, single-base mismatch detection, and Escherichia coli detection [57,58]. Besides DNA-hybridization sensors, AuNP-based piezoelectric biosensors have been used for building devices for ligand sensing by Yu et al. [59]. Literature suggests that using AuNPs reduced the limit of detection by 3 orders of magnitude. Examples of hybrid piezoelectric biosensors include a conjugation of AuNP and hydroxyapatite for surface immobilization of target analyte [60]. This hybrid nanomaterial has multi-adsorption sites and augmented solubility and dispersibility. Using this hybrid material for piezoelectric biosensing, achieved higher sensitivity against analyte molecule in comparison with devices employing only AuNPs or hydroxyapatite.

There has been significant research and advancement in the field of carbon-based nanomaterials in the last couple of decades. The most widely studied and utilized carbon nanomaterials include carbon nanotubes (CNT), graphene (and its derivatives such as graphene-oxide, graphene nanowires etc.) and graphene quantum-dots. Due to their specific structure and electronic configuration, their electromechanical properties are highly attractive for transduction purposes. Similar to other nanostructures, an augmented surfaceto-volume ratio aids in significantly more number of binding sites in comparison with bulk 
materials. Due to such properties, carbon-based materials such as graphene and carbon nanotubes have been integrated with CMOS transistor technology to develop modified transistors and also for biosensing purposes. A more in-depth discussion of carbon-based nanomaterials and their applications in biosensing can be found here [61-64]. The following two sections will provide a broad overview of different types of nano-biosensors based on carbon nanotubes and graphene along with numerous examples from the literature.

\subsection{Carbon Nanotubes}

Carbon nanotubes (CNTs) are cylindrical structures comprising of "rolled-up" sheets of a single-layer of carbon atoms. Depending on their structure, they can be classified as either single-walled or multiwalled. After their discovery in 1991 [65], CNTs have been the subject of significant interest and intrigue due to their unique structural, chemical, and electrical properties. In the last three decades, CNTs have been employed in varied fields of research including nano-electronics and biomedical engineering. Specifically, due to the exponential advance of nanotechnology and nanomanufacturing, CNTs have been widely used to develop novel biosensors. Similar to other nanostructures, CNTs offer a large surface/volume ratio which enables immobilization of much larger quantities of biomolecules on their surface in comparison with bulk materials. Due to their unique properties, CNTs can be exploited to develop novel probes for a variety of biomolecules. For biosensing applications, CNTs can be used as (1) specific capture platforms, (2) probes for transduction of analyte-induced electrical signals, and (3) novel mechanisms of in vivo probing due to the ability of CNTs to cross a biological membrane. Figure 5 shows a generalized example of a CNT-based biosensing technique. Depending on the mechanism of biosensing, CNT-based biosensors can be classified as electrochemical and electronic sensors, immunosensors, and optical biosensors. Such devices are usually extremely sensitive and find applications in the health industry for early-stage detection of biomarkers of a variety of diseases such as cancer. The following sections will briefly discuss these CNT-based biosensors.

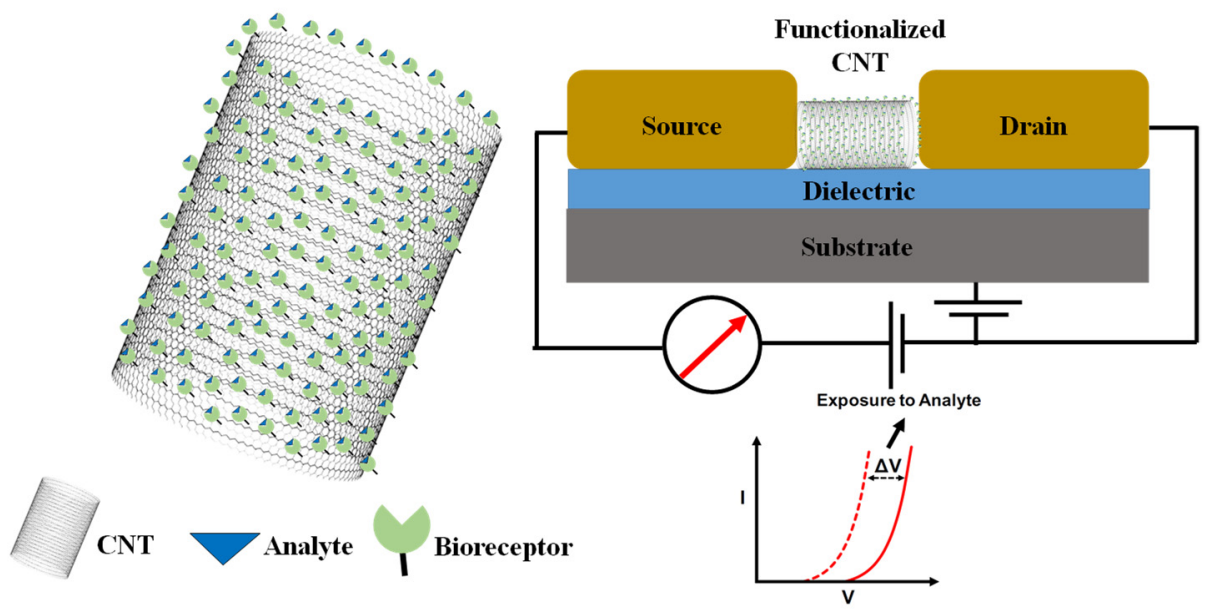

Figure 5. Schematic of carbon nanotube (CNT) functionalized with bioreceptors to facilitate the capture of specific analyte. Schematic of CNT-based field-effect transistor. Successful capture of analyte molecule leads to shift in threshold voltage of the FET device, which is in indirect measure of analyte concentration.

CNT-based electrochemical biosensors: As mentioned above, electrochemical biosensors are designed for transduction of biochemical signals into measurable electrical signals. These sensors have been widely used due to their low cost, ease of fabrication, and use as well as small footprint. Like AuNPs, CNTs have the ability to enhance the electron transfer which make them ideal additions to electrochemical biosensors. CNTs display a high surface-to-volume ratio, augmented sensitivity, electrical conductivity, and chem- 
ical stability, as well as high electrocatalytic effect, which make them ideal candidates for biosensors which require enzymatic reactions for accurate sensing. Therefore, a wide variety of CNT-based electrochemical sensors have been developed in the last two decades. For example, Wang et al. developed such devices for detecting metabolites and protein biomarkers [66]. CNTs have also been used for developing sensitive glucose sensors. The structural self-alignment of glucose oxidase on electrodes using SWNTs as conduction paths between enzyme redox centers and probing electrodes have been demonstrated by Patolsky et al. [67]. Using similar principles, CNT-based biosensors have been developed for accurate sensing of cholesterol, using electrodes functionalized with holesterolesterase, peroxidase, and oxidase [68]. Santos et al. demonstrated biosensors employing functionalized CNTs which can detect nitric oxide [69]. Similarly, Prasad et al. developed an epinephrine sensor and Kress et al. built a dopamine sensor in rats based on CNTs [70,71]. ZeladaGuillen et al. demonstrated a novel aptamaer-based sensor, which used CNTs grafted with protein-specific RNA aptamers, for detection of certain glycoproteins in blood [72]. Some additional examples of similar biosensors include Zhang et al. demonstrating the detection of cellular nitric oxide by single-stranded d(AT) 15 DNA oligonucleotide curled around CNTs, and Jin et al. building SWNT-based hydrogen peroxide biosensors [73,74]. Based on the method of transduction, electrochemical biosensors can be further classified as either potentiometric, amperometric, conductometric, piezoelectric, or voltametric. For example, Fei et al. developed a cysteine detector using $\mathrm{Pt} / \mathrm{CNT}$ electrodes based on principles of cyclic voltammetry [75]. Antiochia et al. fabricated an amperometric PSA sensor using PSA-antibody coated on CNTs [76].

CNT-based optical biosensors: As describe in previous sections, optical biosensors are designed to realize a measurable transduction between the presence or change in concentration of the analyte of interest and the optical properties of the biosensor. Lubbers and Oppitz were the first to develop an optical biosensor for $\mathrm{CO}_{2}, \mathrm{O}_{2}$, and alcohol detection [77]. Since then, there has been widespread interest in developing optical biosensors for detecting, investigating, and quantifying biological processes in vitro and in vivo. Such biosensors can be classified based on their specific optical transduction mechanism, for example surface-plasmon resonance, fluorescence, absorbance/reflectance, etc. These sensors can be further classified as either probing or reacting. Probing sensors provide optical information depending on the differences in interactions between the analyte and the sensor, whereas reacting sensors provide different optical responses based on biologically induced chemical reactions. CNTs have also been widely pursued as an attractive addition to the already-existing biosensing principles to develop novel biosensor technology. Inherently, unfunctionalized CNTs have displayed useful characteristics such as low fluorescence stability, intensity, and biocompatibility. However, after being appropriately functionalized, CNTs can be engineered to display changes in fluorescent emission signals upon exposure to the intended analyte. Additionally, CNTs have been employed to detect changes in local dielectric function and also have displayed augmented resistance to unwanted photobleaching affects, which makes them attractive candidates for optical biosensor applications. For example, NIR detection of adenosine-5'-triphosphate (ATP) living cells have been demonstrated by Kim et al. using CNT/luciferase conjugates [78]. Heller et al. have demonstrated a nitroaromatics sensor, using principles of photoluminescence in the NIR spectrum, based on CNTs functionalized with peptides [79]. CNTs functionalized with genetically altered M13 have also been used for deep-tissue imaging [80]. Using similar principles, single-walled CNTs, functionalized with oligonucleotide labelled dies, have been used by Yang et al. to develop an optical biosensor for single-stranded DNA [81]. In these sensors, the fluorescence of the CNT composite quenched until the single-stranded DNA binds and released the labeled oligonucleotide from the CNTs. Polymers dispersed with CNTs have been used to optically detect different metabolites (riboflavin, L-thyroxine, and oestradiol). Zhang et al. developed a label-free optical sensor for the protein, troponin $\mathrm{T}$, using CNTs functionalized by chitosan using NIR fluorescence techniques $[82,83]$. 


\subsection{Graphene}

Graphene was first theoretically explored by P.R. Wallace in 1947 [84] and then later synthesized by the novel prize-winning scientist, Konstantin Novoselov and his team using a simple scotch-tape dispenser [85]. Graphene and is a carbon structure with sp2 hybridization in two dimensions and can be viewed as "carbon-sheets". These sheets can then either be stacked horizontally to form a 3D graphite structure or can be simply rolled to form nanotubes. Due to the $\pi$-conjugation present in the graphene structure, it exhibits excellent thermal, electrical and mechanical properties. Graphene can be synthesized using a variety of techniques, including chemical vapor deposition (CVD), exfoliation of graphite, liquid phase exfoliation of graphite, reduction of graphene oxide, surface segregation and molecular beam epitaxy. However, most of these are low-throughput techniques, and unfortunately, there has been limited advancement in repeatable and thorough batch-fabrication of graphene. Using techniques such as atomic-force microscopy (AFM), scanning tunneling microscopy (STM) and Raman spectroscopy the most vital properties of graphene have been determined as follows: the surface area of a single-layer of graphene is $\sim 2630 \mathrm{~m}^{2} \mathrm{~g}^{-1}$, and the Young's modulus is $1 \mathrm{TPa}$ with an intrinsic mobility of $2 \times 10^{5} \mathrm{~cm}^{2} \mathrm{v}^{-1} \mathrm{~s}^{-1}$. The thermal conductivity of graphene has been determined as $5 \times 10^{3} \mathrm{Wm}^{-1} \mathrm{~K}^{-1}$. It is optically almost transparent with a measured transmittance of $97.7 \%$, and it is extremely conductive with a conductivity of $\sim 104 \Omega^{-1} \mathrm{~cm}^{-1}$. Amongst its widespread applications, graphene has been mostly used to build high-speed electronic devices for storage and energy harvesting. It has been used to fabricate high-frequency transistors, photodetectors, and biosensors for a plethora of applications such as DNA sequencing. Figure 6 shows a functionalized graphene layer and the working principle of a graphene-based electrochemical biosensor. The following sections will briefly discuss the graphene-based electrochemical biosensors.

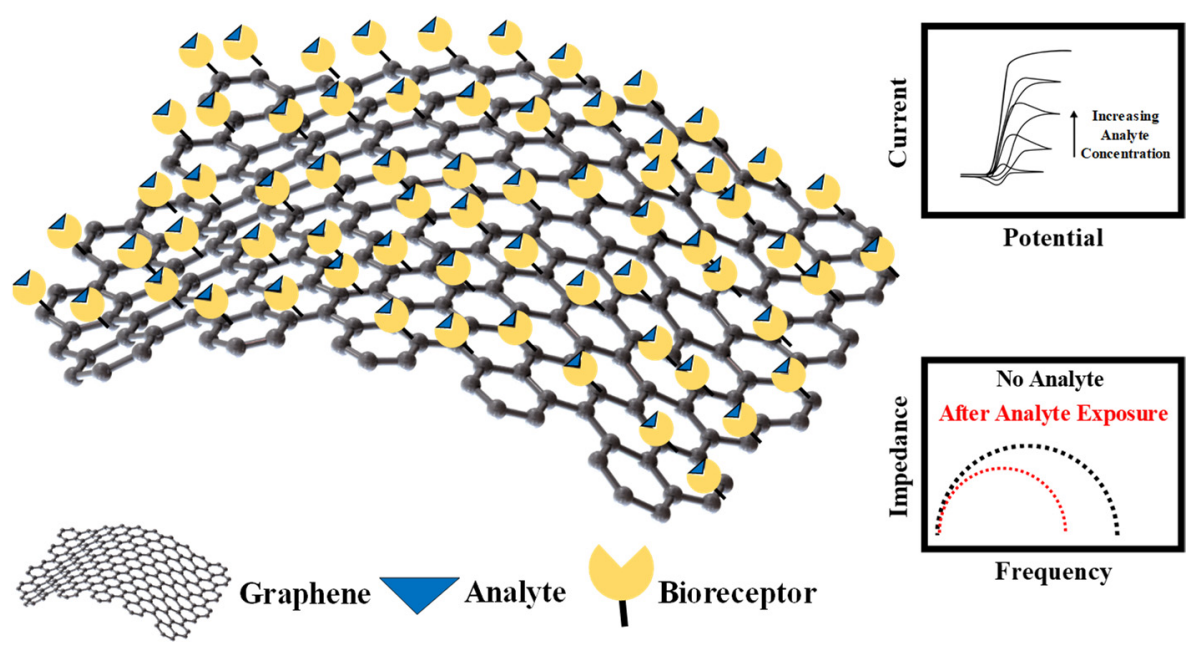

Figure 6. Schematic showing analyte capture by appropriately functionalized graphene monolayer. The capture can be electrically measured by recording the impedance properties of the graphene layer, before and after analyte capture. Additionally, cyclic voltammetry measurements of the graphene layers display a change in I-V plots as a function of analyte concentration.

Graphene-based electrochemical biosensors: As mentioned above, due to its excellent electrical properties, graphene can be integrated with the electrodes of electrochemical biosensors for enhanced biosensing. In addition to graphene's augmented conductivity, it is chemically stable, has low cost, and is electrochemically inert. However, in certain cases, graphene has also been used as a catalyst for numerous biochemical redox reactions. In such biosensors, enzymes are immobilized on the graphene layer, which are used for specific analyte-recognition purposes. The immobilization can be realized using a variety of techniques including adsorption technique, covalent binding, electro-polymerization, 
and layer-by-layer immobilization. Amongst the variety of applications of graphenebased electrochemical biosensors, the most important are the detection of heavy metals, phenols, pesticides, and other pollutants such as hydrogen peroxide or microorganisms for environmental-monitoring purposes. Electrochemical sensors, based on principles of potentiometry and voltammetry, have been widely pursued to detect the presence of heavy metals and are being pursued widely due to their low cost, portability, reduced response time, and augmented sensitivity. The literature shows that electrochemical sensors for detecting heavy metals make use of noble metals such as Au and Pt for electrodes or different forms of carbon [86]. Specifically, carbon-based nanomaterials are effective adsorbents of heavy metals and have been often used as heavy metal scrubbers for cleaning purposes. Therefore, it follows that such materials have widespread application in biosensors for heavy-metal detection. Amongst all carbon-based materials, graphene is the most affective in adsorbing organic and inorganic pollutants. For example, Kong et al. demonstrated a graphene-based electrochemical biosensor for detecting low concentrations of $\mathrm{Cu}^{2+}(1.5 \mathrm{nM})$ and $\mathrm{Pb}^{2+}(0.4 \mathrm{nM})$, based on principles of square-waver voltammetry analysis techniques [87]. In this device, the gold electrode of the sensor was functionalized with aryl diazonium salt followed by the immobilization of covalently bonded graphene sheets. The use of inorganic nanoparticles, such as salts, is required to prevent the formation of graphene agglomerates due to its hydrophobic nature. Hybrid polymer/graphene materials have also been used to detect $\mathrm{Cu}^{2+}$ and $\mathrm{Pb}^{2+}$ to further lower the limit of detection. Zhou et al. developed a biosensor for detecting $\mathrm{Pb}^{2+}$ using graphene-quantum-dot structures. These modified quantum dots were fabricated from graphene oxide, which were powdered into smaller pieces and chemically reduced using the green's technique with polystyrene sulfonate and L-ascorbic acid [88]. Another such example is where an array of AuNPs were immobilized over graphene sheets for detection of $\mathrm{Hg}^{2+}$. Another highly sensitive and selective technique of detecting $\mathrm{Hg}^{2+}$ is by using graphene functionalized with aptamers [89]. The limit of detection was determined to be $\sim 10 \mathrm{pM}$. Graphene and AuNP composites have also been utilized for the specific detection of $\mathrm{Cr}$ (VI) [90]. Graphene has also been utilized for the detection of another commonly found toxic material-phenols. Although phenols, such as Bisphenol A, are electroactive compounds, the electrochemical response is arduous to measure. The electrical properties of graphene have been employed as catalysts for these electrochemical reactions. Graphene sheets which have been negatively doped have been used for sensitive detection of Bisphenol A [91,92]. Another interesting approach of low limit of phenol detection was presented when graphene was functionalized with enzymes immobilized with glutaraldehyde [93]. Recently, stacked layers of graphene in the form of $\mu$-pillars, immobilized with enzymes were used to amperometrically detect $50 \mathrm{nM}$ of phenols [94]. Some other techniques frequently used to amplify the detection capabilities of phenols include modification of graphene with $\beta$-cyclodextrin for low-limit detection $(0.09 \mu \mathrm{M})$ of 2-chlorophenol and 3-chlorophenol. The nanocavities of $\beta$-cyclodextrin help in magnifying the surface-to-volume ratio and improve transduction capabilities and output signal [95]. The literature suggests that electrostatic interactions between enzymes and graphene generally lead to a heightened adsorption of enzyme on the graphene surface, and graphene's electrocatalytic properties help improve the analytical response of such biosensors. For example, acetylcholinesterase immobilized on graphene has been used to detect the presence of pesticides such as organophosphates [96]. The principle behind the detection of these molecules is that organophosphates generally inhibit the enzymes which are immobilized on the graphene sheets. This results in an "oxidation current", which is a measurement of the concentration of organophosphate molecules. Polymers such as Nafion have been used for improved enzyme immobilization on graphene. For example, a combination of Nafion and graphene-oxide have been used to form a nanocomposite which is used to modify the biosensor electrode followed by enzyme immobilization for the detection of organophosphates such as dichlorvos [97]. Another similar biosensor was developed which included organophosphorus hydrolase enzyme, immobilized in Nafion, for the detection of paraoxon. The fabricated device 
displayed excellent electrochemical properties, high sensitivity, fast response and low limit of detection [98]. Graphene has also been integrated with metallic nanoparticles to develop sensitive biosensors for detection of organophosphate molecules. For example, graphene sheets with AuNPs and poly(diallyldimethylammonium chloride) immobilized with the enzyme acetylcholinesterase, allow for much greater enzyme activity, and this phenomenon is used for highly sensitive detection of organophosphate molecules [99]. The addition of metallic nanoparticles to graphene-based biosensors, provides much greater electrocatalytic activity, thereby allowing for a much lower limit of detection. In addition to metallic nanoparticles, CNTs have also been employed (in combination with dispersants like Polyaniline) to reinforce such biosensors since they have the ability to aid in electron transfer between analyte molecules and the probing electrodes, which helps in the realization of sensitive detection of the analyte. Other biosensors used for similar purposes include nonenzymatic biosensors which comprise of a hybrid stack of graphene and CNT for detecting organophosphates such as methyle parathion [100]. Another example of such an electrochemical biosensor is based on cobalt (III) oxide (CoO)-reduced graphene oxide, which was developed for the purposes of detecting carbofuran and carbaryl in agricultural produce [101]. Generally, nonenzymatic graphene biosensors have displayed greater stability in sensor response, as compared to the enzyme-assisted-based sensing of pesticides such as organophosphates. Besides heavy metals and pesticides, graphene-based biosensors have been used to detect the presence of hydrogen peroxide and certain micro-organisms. Zhou et al. developed a biosensor which comprised of hybrid-multilayers of graphene and chitosan with microperoxidase salt as a probing electrode [102]. This configuration allowed for a low limit of detection $(2.5 \mu \mathrm{M})$ of $\mathrm{H}_{2} \mathrm{O}_{2}$. Song et al. reported a similar device which comprised of a multilayer electrode, consisting of molybdenum-disulfide-graphene and horseradish peroxidase for an ultralow limit of detection of $\mathrm{H}_{2} \mathrm{O}_{2}$ [103]. Escherichia coli (E. coli) has been previously detected using graphene-based biosensors using functionalized graphene layers. The literature suggests that probing electrodes which comprise of a hybrid graphene and CNT layer, as well as the presence of graphene oxide, provides a higher probability of E. coli capture compared to bare graphene [104]. In other configurations, specific detection of bacteria is enabled by functionalizing the graphene layer with antibodies specific to the bacteria intended to be captured [105]. Another type of biosensor for E. coli detection, which does not involve the use of antibodies is based on using the adsorption of the slightly negatively charged $E$. coli on the surface of the p-type graphene. Another bacterium which has been similarly detected (using either antibodies or aptamers) using graphene-based biosensors is Staphylococcus aureus [106].

\subsection{Quantum Dots}

Quantum dots are colloidal nanostructures mostly built using semiconductor materials belonging to the groups of II-VI, III-V, or IV-VI in the modern periodic table. Due to quantum-mechanical effects, quantum dots display opto-electrical properties which are significantly different that conventional bulk materials. These properties make quantum dots attractive candidates for biosensing purposes. Alivisatos and Nie were the first to develop a quantum-dot biosensor and imaging system based on fluorescence in 1998 [107,108]. Since then, quantum dots have been widely used for biosensing purposes. The fluorescent properties of quantum dots can be tuned simply by altering their geometrical measurements, and therefore, using them is advantageous in comparison with traditional fluorescent materials such as proteins or organic dyes. Additionally, quantum dots display enhanced brightness and stability against bleaching compared to traditional fluorescent materials. These nanostructures can also be easily functionalized with a plethora of biomolecules such as antibodies, peptides, and DNA to realize modified quantum dot probes which interact with other biomolecules with an augmented level of specificity. Quantum dots have also been used in combination with traditional metallic probing electrodes since they display photo-electrochemical properties. For example, quantum dots which have been immobilized on electrodes display enhanced electrical activity and electron trans- 
fer between themselves and the electrode when exposed to certain wavelengths of light. These properties of quantum dots have led to widespread research and development in the field of quantum-dot-based biosensors. Based on their sensing mechanism, we can classify these biosensors as (1) fluorescent, (2) bioluminescent, (3) chemiluminescent, and (4) photo-electromechanical. Figure 7 is a schematic of the working principle of a quantum-dot-based biosensor.
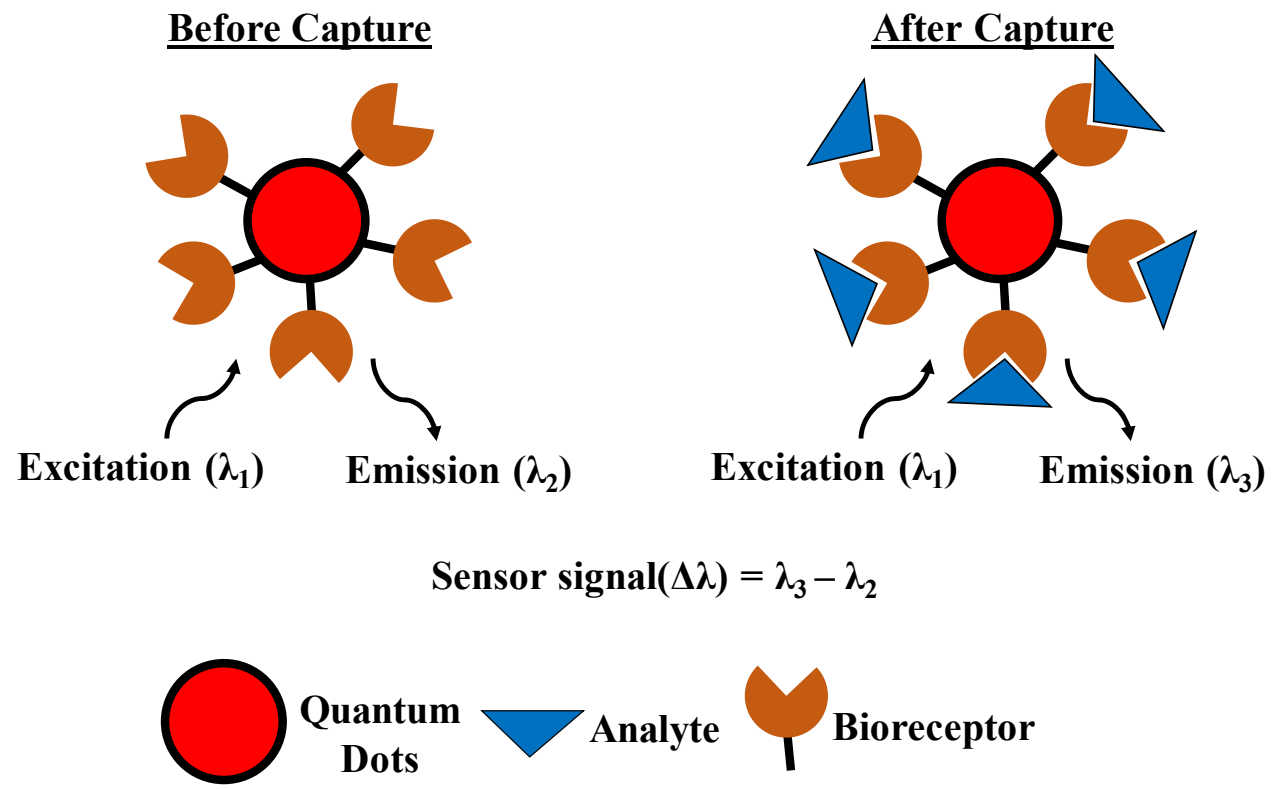

Figure 7. Schematic representation of fluorescence resonance energy transfer in quantum-dot-based biosensors. Successful capture of analyte results in change in the wavelength of emitted light. This change is a measure of captured analyte.

Quantum-dot-based fluorescent biosensors: As mentioned above, its high sensitivity and enhanced stability as well as abilities to measure different analytes simultaneously have led to significant development of quantum-dot-based fluorescent biosensors. Fluorescencebased resonant energy transfer is the most widely used technique for quantum-dot-based biosensors. The advantage of the resonant technique is that it enables detection of target biomolecules without any requirement of washing and separation steps. Additionally, high SNR (signal-to-noise ratio) and highly sensitive techniques such as single-molecule detection methods have been used for quantum-dot-based biosensors for the detection of biomolecules such as DNAs, DNA methylation, and numerous enzymes. For example, Zhang et al. developed a DNA assay where liposomes encapsulated hundreds of quantum-dots to form hybrid complexes to enable binding of target DNA. This technique was used to accurately and simultaneously detect genetic sequences of HIV-1 and HIV-2 at 10-18 molar concentrations [109]. Shamsipur et al. demonstrated a quantum-dot-based biosensor using resonant-energy transfer techniques for nanomolar concentration detections of Helicobacter pylori-specific DNA [110]. Krull et al. developed a point-of-care rapid diagnostic paper-based nucleic-acid assay using quantum dots with fluorescent resonantenergy transfer techniques [111]. This device exhibited highly specific and sensitive ( fmol concentration) detection of Cy3-DNA hybridization. Zhang et al. demonstrated sensitive and high SNR detection of DNA methylation using a single quantum-dot-based biosensor [112]. Using fluorescence-based resonant-energy transfer techniques, Hildebrandt and Qiu demonstrated quantum-dot-based simultaneous detection of three different microRNAs: hsa-miR-20a-5p, hsa-miR-20b-5p, and hsa-miR-21-5p [113]. Zhang et al. improved on this work by demonstrating multiplexed biosensing using a single quantum-dot-based biosensor by employing fluorescent resonant-energy transfer techniques [114]. Ho et al. developed a quantum-dot-based fluorescent biosensor for sensitive detection of miR-141 
in prostate cancer with a detection limit of $1 \mathrm{pM}$ [115]. Wang et al. developed a quantumdot-based fluorescent biosensor for the detection of DNA and microRNA [116]. Sang and Wang et al. fabricated a quantum-dot-based fluorescent biosensor for accurate detection of ten different glycoproteins using fluorescence polarization techniques with a limit of detection of $0.15 \mu \mathrm{M}$ [117]. Hildebrandt et al. built a quantum-dot-based immunosensor for highly sensitive $(1.6 \mathrm{ng} / \mathrm{mL})$ detection of prostate-specific antigens in $50 \mu \mathrm{L}$ serum samples for prostate-cancer diagnosis [118]. Based on the quenching property of $\mathrm{H}_{2} \mathrm{O}_{2}$, Tang et al. demonstrated a paper-based biosensor for accurate detection of carcinoembryonic antigen with a limit-of-detection of $\sim 6.7 \mathrm{pg} / \mathrm{mL}$ [119]. Using similar principles, Zhang et al. developed a quantum-dot-based biosensor for simultaneously detecting multiple proteins by using a protein-binding dye bromophenol blue [120]. Kim et al. built a quantum-dot-based immunosensor for enzyme-less and ultrasensitive detection ( $<10-18$ molar concentration) of the protein myoglobin [109]. Tyrakowski and Snee fabricated an antibody-free quantumdot-based highly sensitive biosensor (with a limit of detection $\sim 3.06 \mathrm{pmol} / \mathrm{mL}$ ) for sensitive detection of streptavidin [121]. Li et al. demonstrated a fluorescent-based caspase assay based on the principles of inner-filter effect of mobilized AuNPs immobilized on quantumdot fluorescence and achieved detection in the range of $\mathrm{pM}$ concentration [122]. Zhang et al. fabricated a quantum-dot-based biosensor for sensitive detection of DNA glycosylase activity with human 8-oxoguanine-DNA glycosylase 1. Zhang et al. developed a single quantum-dot-based fluorescent biosensor for highly sensitive detection of DNA methyltransferase [123]. The same group fabricated a single quantum-dot-based biosensor for rapid and highly sensitive detection of terminal deoxynucleotidyl transferase activity. Petryayeva and Algar built a quantum-dot-based fluorescent biosensor for sensitive detection of three different proteolytic enzymes (trypsin, chymotrypsin, and enterokinase), with a limit of detection in the range of $\mathrm{nM}$ concentrations [124]. Using fluorescent techniques, Ngeontae et al. fabricated a quantum-dot-based biosensor for detecting abnormal levels of adenosine-5'-triphosphate (ATP) [125].

Quantum-dot-based bioluminescent biosensors: A major bottleneck to the practical implementation of fluorescent biosensors based on quantum dots is the inherent requirement of appropriate illumination sources. Additionally, such sensors suffer from high background noise signals due to direct excitation of the acceptor fluorophore. This can be solved by using a bioluminescence resonance-energy transfer technique where a bioluminescent luciferase acts as the energy donor which acts as the catalyst for the oxidation of the substrate which generates the emission light and which can then be transferred to the acceptor to complete the bioluminescence resonance-energy transfer process. For example, Shen et al. demonstrated sensitive and selective detection of enrofloxacin using a quantum-dot-based bioluminescent biosensor [126]. Additionally, Jin and Tsuboi fabricated an optical biosensor for the detection of apoptosis cells using quantum-dot biosensors [127].

Quantum-dot-based chemiluminescent biosensors: These devices are based on the principle of emission of light due to a chemical reaction. Quantum dots are exploited for their catalytic properties which can enhance redox chemiluminescent reactions and thereby improve the transduction signal. Therefore, quantum-dot-based chemiluminescent biosensors have been widely developed for their low background noise and high sensitivity. For example, Ju et al. built a quantum-dot-based chemiluminescent biosensor for sensitive detection of a carcino-embryonic antigen with a limit of detection in the range of $24 \mathrm{fg} / \mathrm{mL}$ [128]. Based on similar principles, Yao et al. demonstrated sensitive biosensing of single-stranded-DNA binding protein [129]. Similarly, Zou et al. fabricated an electrogenerated chemiluminescence biosensor, capable of detecting dopamine present in trace amounts in urine and CSF fluid samples [130].

Quantum-dot-based photo-electrochemical biosensors: In these biosensors the analytedependent photoexcitation is the source of transduction energy, which is measured for sensing purposes. Such devices are generally easy and cheap to build and are designed to be portable for practical purposes. They have been used to build highly sensitive sensors for detecting DNAs and proteins. For example, Ju et al. developed photo-electrochemical 
biosensors based on quantum dots, functionalized with $\mathrm{ZnO}$ nanosheets for highly sensitive detection ( $\sim .93 \mathrm{fM}$ concentration) of DNA [131]. Zhu et al. developed similar DNA assays with enhanced sensitivity by using CdTe quantum dots [132]. The limit of detection was measured to be as low as approximately $27 \mathrm{aM}$. Such biosensors have also been used by Chen et al. to detect extremely low levels of cardiac troponin $\mathrm{T}\left(1 \times 10^{-7} \mathrm{~g} / \mathrm{L}\right)$. Chen used CdS quantum dots with $\mathrm{TiO}_{2}$ to realize modified ITO electrodes [132]. Finally, Dai et al. recently fabricated a device for ultrasensitive detection of carcino-embryonic antigen using CdTe quantum dots [133].

The different nanostructures utilized for biosensing, along with their transduction mechanism as well as the limit of detection can be summarized in the Table 1.

Table 1. The different nanostructures utilized for biosensing, along with their transduction technique as well as the limit of detection.

\begin{tabular}{|c|c|c|c|c|}
\hline Nanostructures & $\begin{array}{l}\text { Transduction } \\
\text { Mechanism }\end{array}$ & Analyte & Limit of Detection & Ref. \\
\hline AuNPs & Electrochemical & Tumor markers & $0.1 \mu \mathrm{g} / \mathrm{L}$ & [47] \\
\hline AuNPs & Electrochemical & DNA hybridization & $1.52 \times 10^{-10} \mathrm{~mol} / \mathrm{L}$ & [49] \\
\hline AuNPs & Electrochemical & Glucose & $0.18 \mu \mathrm{M}$ & [48] \\
\hline AuNPs & Electrochemical & $\begin{array}{l}\text { Horseradish } \\
\text { peroxidase }\end{array}$ & $4.01 \times 10^{-7} \mathrm{M}$ & [46] \\
\hline AuNPs & Electrochemical & & & \\
\hline AuNPs & Optical & $\begin{array}{l}\text { Antibody/Antigen } \\
\text { interaction }\end{array}$ & $25 \mathrm{ng} / \mathrm{mL}$ & [36] \\
\hline AuNPs & Optical & $\begin{array}{l}\text { Enzymatic ligation } \\
\text { reactions }\end{array}$ & $1 \mathrm{pM}$ & [39] \\
\hline AuNPs & Optical & $\begin{array}{l}\text { Organophosphorus } \\
\text { pesticides }\end{array}$ & $0.234 \mathrm{ppb}$ & [37] \\
\hline AuNPs & Optical & DNA hybridization & $10 \mathrm{pM}$ & [38] \\
\hline AuNPs & Piezoelectric & Gene sensing & $3.2 \times 10^{-11} \mathrm{M}$ & [56] \\
\hline AuNPs & Piezoelectric & DNA sensing & $10 \mu \mathrm{g} / \mathrm{mL}$ & [55] \\
\hline AuNPs & Piezoelectric & $\begin{array}{c}\text { DNA mutation } \\
\text { detection }\end{array}$ & $2.6 \times 10^{-9} \mathrm{~mol} / \mathrm{L}$ & [57] \\
\hline AuNPs & Piezoelectric & $\alpha$-fetoprotein & $15.3 \mathrm{ng} / \mathrm{mL}$ & [60] \\
\hline AuNPs & Piezoelectric & $\begin{array}{c}\text { rabbit/goat } \\
\text { anti-human IgG }\end{array}$ & $10.9 \mu \mathrm{g} / \mathrm{mL}$ & [59] \\
\hline $\mathrm{CNT}$ & Electrochemical & Fructose & $1.0 \times 10^{-6} \mathrm{~mol} / \mathrm{L}$ & [76] \\
\hline $\mathrm{CNT}$ & Electrochemical & Glucose oxidase & $20 \mathrm{mM}$ & [67] \\
\hline CNT & Electrochemical & L-cysteine & $0.3 \mu \mathrm{M}$ & [75] \\
\hline CNT & Electrochemical & Cholesterol & $100 \mathrm{mg} / \mathrm{dL}$ & [68] \\
\hline CNT & Electrochemical & Surface glycoprotein & $\sim a M$ & [72] \\
\hline $\mathrm{CNT}$ & Electrochemical & Nitric oxide & $25 \mathrm{nM}$ & [69] \\
\hline CNT & Electrochemical & Epinephrine & $0.02 \mathrm{ng} / \mathrm{mL}$ & [70] \\
\hline CNT & Electrochemical & Nitric oxide & $300 \mathrm{nM}$ & [73] \\
\hline
\end{tabular}


Table 1. Cont.

\begin{tabular}{|c|c|c|c|c|}
\hline Nanostructures & $\begin{array}{l}\text { Transduction } \\
\text { Mechanism }\end{array}$ & Analyte & Limit of Detection & Ref. \\
\hline CNT & Optical & Troponin $\mathrm{T}$ & $100 \mathrm{ng} / \mathrm{mL}$ & [82] \\
\hline CNT & Optical & Cellular ATP & $240 \mathrm{nM}$ & [78] \\
\hline $\mathrm{CNT}$ & Optical & Tumor cells & $2 \mu \mathrm{g} / \mathrm{mL}$ & [80] \\
\hline $\mathrm{CNT}$ & Optical & $\begin{array}{l}\text { riboflavin, } \\
\text { L-thyroxine, } \\
\text { oestradiol. }\end{array}$ & $100 \mu \mathrm{M}$ & {$[83,84]$} \\
\hline $\mathrm{CNT}$ & Optical & nitroaromatics & $9 \mu \mathrm{M}$ & [79] \\
\hline Graphene & Electrochemical & $\begin{array}{l}\text { Carbamate } \\
\text { Insecticide }\end{array}$ & $5.32 \times 10^{-8} \mathrm{~g} / \mathrm{L}$ & [100] \\
\hline Graphene & Electrochemical & $\mathrm{Pb}(\mathrm{II})$ and $\mathrm{Cd}(\mathrm{II})$ & $2.1 \mathrm{pM}$ and $81 \mathrm{pM}$ & [86] \\
\hline Graphene & Electrochemical & $\begin{array}{c}\mathrm{Cu}^{2+}, \mathrm{Zn}^{2+}, \mathrm{Fe}^{3+} \\
\mathrm{Pb}^{2+} \text { and } \mathrm{Cr}^{3+}\end{array}$ & & \\
\hline Graphene & Electrochemical & bisphenol A & $5.0 \times 10^{-9} \mathrm{~mol} / \mathrm{L}$ & {$[91,92]$} \\
\hline Graphene & Electrochemical & Cholinesterase & $0.3 \mathrm{ppb}$ & [96] \\
\hline Graphene & Electrochemical & Phenol & $50 \mathrm{nM}$ & [94] \\
\hline Graphene & Electrochemical & $\mathrm{Pb}^{2+}$ & $5.0 \times 10^{-9} \mathrm{M}$ & [88] \\
\hline Graphene & Electrochemical & $\begin{array}{l}\text { Hydroquinone, } \\
\text { resorcinol }\end{array}$ & $\begin{array}{l}5.2 \times 10^{-9} \mathrm{~mol} / \mathrm{L}, \\
2.2 \times 10^{-9} \mathrm{~mol} / \mathrm{L}\end{array}$ & [93] \\
\hline Graphene & Electrochemical & imidacloprid & $2.2 \times 10^{-8} \mathrm{~mol} / \mathrm{L}$ & [99] \\
\hline Graphene & Electrochemical & $\mathrm{Cu}^{2+}$ and $\mathrm{Pb}^{2+}$ & $\begin{array}{c}1.5-20 \mathrm{nM} \text { and } \\
0.4-20 \mathrm{nM}\end{array}$ & [87] \\
\hline Graphene & Electrochemical & $\begin{array}{l}\text { 2-chlorophenol } \\
\text { and 3-chlorophenol }\end{array}$ & 0.2 and $0.09 \mu \mathrm{M}$, & [95] \\
\hline Graphene & Electrochemical & organophosphate & $1.37 \times 10^{-7} \mathrm{M}$ & [98] \\
\hline Graphene & Electrochemical & Mercury & $10 \mathrm{pM}$ & [89] \\
\hline Quantum Dots & Bioluminescent & enrofloxacin & $0.023 \mathrm{ng} / \mathrm{mL}$ & [126] \\
\hline Quantum Dots & Chemiluminescent & Dopamine & $3.0 \mathrm{nM}$ & [130] \\
\hline Quantum Dots & Chemiluminescent & $\begin{array}{c}\text { carcinoembryonic } \\
\text { antigen }\end{array}$ & $24 \mathrm{fg} / \mathrm{mL}$ & {$[128]$} \\
\hline Quantum Dots & Chemiluminescent & $\begin{array}{l}\text { protein-DNA } \\
\text { interactions }\end{array}$ & $0.1 \mathrm{nM}$ & [129] \\
\hline Quantum Dots & Fluorescent & Glycoproteins & $0.15 \mu \mathrm{M}$ & [117] \\
\hline Quantum Dots & Fluorescent & $\begin{array}{c}\text { Nucleic acid } \\
\text { hybridization }\end{array}$ & $300 \mathrm{fmol}$ & [111] \\
\hline Quantum Dots & Fluorescent & MicroRNA & $<1 \mathrm{pM}$ & [113] \\
\hline Quantum Dots & Fluorescent & $\begin{array}{c}\text { DNA and } \\
\text { MicroRNA }\end{array}$ & $1 \mathrm{fM}$ and $10 \mathrm{fM}$ & {$[116]$} \\
\hline Quantum Dots & Fluorescent & $\begin{array}{l}\text { miR-141 prostate } \\
\text { cancer biomarker }\end{array}$ & $1.00 \times 10^{-12} \mathrm{M}$ & [115] \\
\hline Quantum Dots & Fluorescent & 5-methylcytosine & $1 \mathrm{aM}$ & [112] \\
\hline Quantum Dots & Fluorescent & MicroRNA & $1.6 \times 10^{-17} \mathrm{M}$ & [114] \\
\hline
\end{tabular}


Table 1. Cont.

\begin{tabular}{lcccc}
\hline Nanostructures & $\begin{array}{c}\text { Transduction } \\
\text { Mechanism }\end{array}$ & Analyte & Limit of Detection & Ref. \\
\hline Quantum Dots & Fluorescent & DNA & $<1 \mathrm{aM}$ & {$[109]$} \\
\hline Quantum Dots & Fluorescent & $\begin{array}{c}\text { prostate specific } \\
\text { antigen }\end{array}$ & $1.6 \mathrm{ng} / \mathrm{m}$ & {$[118]$} \\
\hline Quantum Dots & Fluorescent & Helicobacter pylori & $4.5 \times 10^{-9} \mathrm{M}$ & {$[110]$} \\
\hline Quantum Dots & $\begin{array}{c}\text { Photo- } \\
\text { electrochemical }\end{array}$ & $\begin{array}{c}\text { Carcino-embryonic } \\
\text { antigen }\end{array}$ & $0.47 \mathrm{pg} / \mathrm{mL}$ & {$[133]$} \\
\hline Quantum Dots & $\begin{array}{c}\text { Photo- } \\
\text { electrochemical }\end{array}$ & DNA & $27 \mathrm{aM}$ & {$[132]$} \\
\hline Quantum Dots & $\begin{array}{c}\text { Photo- } \\
\text { electrochemical }\end{array}$ & DNA & $<1 \mathrm{fM}$ & {$[131]$} \\
\hline
\end{tabular}

\section{Nano-Biosensors for Cancer Detection and Future Prospective Including the Internet of Things and the Role of Machine Learning in Smart Biosensing}

In the previous sections, the article provided an extensive overview of biosensors comprising of nanofilms/structures and their many applications. In this section, we provide a brief review of the application of such biosensors specifically in two extremely important fields of research: (1) cancer diagnostics and (2) low-power, portable sensing techniques for Internet of things (IoT) applications.

\subsection{Cancer Diagnosis}

Due to its high mortality rate, cancer has been the subject of widespread and incessant research over the globe. On account of their enhanced sensitivity, selectivity, ease-of-use, and superior analytical performance for rapid sensing, nanostructure-based biosensors are highly attractive candidates for cancer detection. The following sections will provide a brief literature survey of nanostructure-based biosensors and biosensing techniques which employ nanostructures for cancer diagnosis.

CNT-based biosensors: Feng et al. developed a paper-based bipolar electrode, functionalized with multiwall CNTs for sensitive electrochemiluminescent detection of prostate specific antigen(PSA) [134]. Baj-Rossi et al. demonstrated CNT-based biosensors for the detection of drugs aimed at treatment of breast cancer [135]. Ovádeková et al. developed a screen-printed carbon electrode, modified by CNTs and AuNPs, for the detection of berberine, an isoquinoline plant alkaloid which demonstrates significant antimicrobial and anticancer activity [136]. Liu et al. fabricated a biosensor which comprised of tricosane-functionalized single-walled CNTs for sensitive detection of VOCs present in the breath, which are a potential indication of lung cancer [137]. Park et al. built a CNT-based biosensor for detection of the cancer marker galactin-3 [138]. Zheng et al. demonstrated electrochemical detection of HeLa and HL60 cancer cells using folic-acid -unctionalized polydopamine-coated CNTs [139]. Fayazfar et al. built a sensitive label-free detection platform for sensing TP53 gene mutation [140]. Shobha et al. demonstrated early-stage detection of prostate cancer using CNTs functionalized with specific DNA strands [141]. Lerner et al. fabricated a CNT-based field-effect transistor, an immunosensor for detection of osteopontin, which is a biomarker of prostate cancer [142]. Abdolahad et al. used vertically aligned CNTs for the detection of SW48 cells from grade IV human colon tumors [143]. Liu et al. developed a multilayer CNT-based biosensor for the detection of liver cancer cells [144]. Veetil and Ye et al. developed CNT-based immunosensors for probing cancer biomarkers [145]. Malhotra et al. demonstrated ultrasensitive electrochemical immunosensing based on CNTs for detecting very low concentrations of interleukin-6 (Il-6) [146]. Wan et al. demonstrated simultaneous detection of PSA and interleukin-8 (Il-8) using screen-printed carbon electrodes [147]. Arkan et al. fabricated a biosensor for detection of HER2 in breast-cancer patients, which comprised of AuNP immobilized on 
CNT liquid electrodes [148]. Zerda et al. developed optical CNT biosensors for detection of alpha(v) beta(3) integrins [149]. Wang et al. developed a highly sensitive fluorescent assay for detecting ultralow concentrations of cyclin A peptide, which is overexpressed in certain human cancers [150].

Quantum-dot-based biosensors: Ho and Wilner et al. demonstrated a quantum-dotbased biosensor for the detection of miR-141 in prostate cancer [115]. Zhang et al. developed a quantum-dot biosensor for rapid detection of terminal deoxynucleotidyl transferase (TdT), which is a biomarker for leukemic disease [151]. Kim et al. demonstrated fluorescence imaging of metalloprotein in cancer cells using quantum-dot-based fluorescent probes [152]. Jie et al. demonstrated highly sensitive cancer-cell detection ( 98 cells $/ \mathrm{mL}$ ) using amplified electrochemiluminescent biosensors employing magnetic quantum dots [153].

Surface-plasmon resonance-based biosensors: Surface-plasmon resonance (SPR)-based biosensors have been actively used for detecting cancer biomarkers in serum samples [154] Using similar techniques, sensitive detection of carcino-embryonic antigen has also been reported [155]. Carcino-embryonic antigen is associated with colorectal and lung cancers. Other examples of SPR-based biosensor applications for cancer-cell detection include ultrasensitive detection of prostate-specific antigen, tumor markers, human chronic gonadotropin, leukocyte cell adhesion molecules, breast cancers, and oral cancers [156-159]. Prasad et al. demonstrated SPR-based ultrasensitive biosensing of tumor necrosis factor alpha (TNF- $\alpha$ ) at concentrations in the range of fmol [160]. Another example is the use of RNA aptamer microarrays and sensitive SPR techniques for the detection of vascular endothelial growth factor (VEGF) (at 1 pM concentration), a biomarker for lung cancer, breast cancer, and colorectal cancer [161]. Jang et al. demonstrated highly sensitive detection of a prostate specific antigen (PSA) using optical fiber SPR techniques which employed the use of sandwich assay and analyte-specific antibodies [162]. Similar techniques have also been used for detection of oral-cancer biomarkers. Another method of ultrasensitive detection of PSA was demonstrated by the use of super-paramagnetic particles with biomarker-specific antibodies and SPR techniques [163]. The limit of detection was determined to be $10 \mathrm{fg} / \mathrm{mL}$. Similar biosensors have also been used for sensitive detection of pituitary hormones [164]

Quartz crystal microbalance (QCM)-based biosensors: QCM-based biosensors integrated with nanoparticles have been used for sensitive detection of PSA and PSA-alpha 1-antichymotrypsin biomarkers, with a limit of detection measured in the range of $0.29 \mathrm{ng} / \mathrm{mL}$ [165]. QCM techniques have also been used for enhancing the output signals of electrochemical impedance spectroscopy sensors by employing DNA aptamers against PSA by using thiol-mediated surface chemistry modification of Au surface on the sensor [166]. Wang et al. used QCM techniques for detecting single-nucleotide polymorphism in the p53 tumor suppressor gene [167]. QCM biosensors have been used with AuNPs to demonstrate highly sensitive detection of hybridization of DNA fragments of the p53 gene near codon 248 [168]. Similar techniques have also been employed to detect the p16 gene. Poly (2-hydroxyethyl methacrylate) (PHEMA) nanoparticle-assisted QCM techniques have also been used for sensitive and accurate detection of breast-cancer cells including MCF7 and MDA-MB 231 [169].

Magnetic nanoparticles-based biosensors: Functionalized magnetic nanoparticles are vital for noninvasive and highly sensitive detection of cancer cells. Kumar et al. utilized magnetic nanoparticles, functionalized with target-specific peptides for enhanced tumor uptake and more pronounced silencing effects [170]. These magnetic nanoparticles are generally iron-based magnetic oxides due to their properties of biocompatibility, saturation magnetization, and resistance against oxidation processes. Extensive details of such nanoparticles and their applications in the field of cancer research can be found in these literature references [171-180]. 


\subsection{Low-Power Sensors for Internet of Things}

With the meteoric rise of the Internet of things (IoT) in the last two decades, humanity is on the verge of witnessing the advent of a new digital nervous system for the world. With the practical deployment of an interconnected network of cameras, microphones, and a plethora of sensor and actuator systems, we seem to be inching toward a truly "smart" society. The earliest realization of the IoT was in 1982 when a group of local programmers at Carnegie Melon University connected a Coca-Cola machine to the internet to check if there was a drink available in the machine and if it was cold. With the term "Internet of things" being coined in 1999, the practical implications of this technology have been widespread in the last twenty years, and it has evolved immensely. By the year 2013, the IoT became an amalgamation of various technologies, including the internet, wireless communication, GPS, embedded systems, and MEMS devices. The latest advances in the IoT technology include development of smart wearable electronics for health monitoring, smart homes, pre-integrated IoT platforms, merging of artificial intelligence, and machine-learning algorithms with stand-alone devices and implementation of low-cost and power-efficient sensors and sensor-networks.

At the backbone of the entire IoT framework lies a variety of sensors and sensor systems that collect diverse data and share it across the network of interconnected smart devices. This makes it possible for these devices to operate autonomously and improve the effectiveness and functionality of the vast IoT network. Some of the critical sensors which are being extensively used for these purposes are temperature, proximity and pressure sensors, water and air-quality monitoring sensors, and IR sensors. However, the practical realization of such an omnipresent and densely interconnected system demands the availability of low-power sensors and sensor systems for energy-efficient device operation and communication between the smart devices. For example, continuous air quality monitoring and asset tracking requires the sensors to be battery operated and deployed in remote areas of the world. Furthermore, to minimize energy consumption, most of these sensors are designed to typically operate in "sleep" or "stand-by" mode where it consumes very low power and record data only in the presence of a stimulus or according to a predetermined operation protocol. Research intended for the development of low-power sensors and sensor systems for IoT-based applications has been actively pursued by a significant proportion of the scientific community in the last couple of years and has led to major advancements in the field of nanotechnology-based sensor and sensor systems. The following section provides some key references across this field.

Chikkadi et al. demonstrated the ultra-low-power operation of self-heated, suspended carbon-nanotube gas sensors [181]. Ngoc and Wang presented the design and fabrication of low-power and self-sustaining $\mathrm{SnO}_{2}$ nanowire gas sensors for IoT and portable applications [182,183]. Liu et al. demonstrated low-power gas sensors fabricated using silicon nanowires $/ \mathrm{TiO}_{2}$ core-shell heterojunctions [184]. Han et al. proposed a new low-power gas sensor utilizing 1-D Si nanowire and 2- $\mathrm{D} \mathrm{SnO}_{2}$ thin films [185].Cho demonstrated a novel low-power-consuming and high-sensitivity Schottky $\mathrm{H}_{2}$ sensor based on Si nanomembranes [186]. Alreshaid and Stetter discussed multiple ink-jet-printed nano-sensors for IoT and smart-city applications $[187,188]$. Mamun et al. described various wearable sensors for environmental monitoring for IoT applications [189]. Long et al. demonstrated low-power gas sensing using 3D porous nanostructured metal-oxide sensors for application related to the IoT [190]. Weiss provided an elaborate discussion of low-power and highly-sensitive magnetic sensors [191]. Villani et al. describe a novel self-sustaining ultra-low noninvasive voltage/current sensor for IoT-based solutions [192]. Kassal et al. demonstrated the development and characterization of an ultra-low-power radio-frequency identification sensor tag for use in IoT-based applications [193]. Laubhan et al. proposed the implementation of a low-power IoT wireless sensor network for the detection of motion, humidity, and temperature [194]. Kuo et al. presented a design of a low-power and long-range sensor node for the next-generation IoT platform [195]. Kamakshi et al. proposed a design for a nano-Wattpowered CMOS temperature sensor for ultra-low-power IoT applications [196]. Garulli 
et al. described a smart temperature-sensor design based on the architecture of CMOS $65 \mathrm{~nm}$ technology for use in the IoT network [197]. Kim et al. have recently developed a novel sensing technique for highly sensitive biosensing based on the quantum-tunneling effect using nanogap break-junctions [198-206]. Furthermore, Mastrangelo et al. have also been responsible for developing zero-power and highly sensitive polymeric sensors for VOC detection [207-213].

IoT sensors in the field of healthcare is also an active area of research. Beach et al. presented an ultra-low-power ECG monitor integrated with the SPHERE IoT platform [214]. Xican et al. provide low-power sensor designs for IoT and mobile healthcare applications [215]. Gatouillat et al. describe the development and evaluation of an ECG-based cardiorespiratory IoT sensor [216]. Medu et al. describe low-power memory technology for sensors related to IoT-based wearables and portable medical devices [217].

Researchers worldwide are highly invested in developing state-of-the-art sensor-nodes / systems and system architecture catered to IoT applications. For example, Hayashikoshi and Gogoi proposed a low-power multi-sensor platform for IoT applications [218,219]. Tresanchez et al. describe the design of a cost-effective and low-power embedded wireless image sensor node for IoT applications [220]. Fayyazi et al. describe an ultra-low-power memrisitive neuromorphic circuit for IoT-based smart sensors [221]. Ameloot et al. provide a low-power, autonomous, compact, wireless IoT sensor node based on LoRa and SigFox technologies [221]. Ma et al. introduced a visible light-enabled indoor localization system for low-power IoT sensors [222]. Mois et al. evaluated self-powered environmental monitoring systems that use Bluetooth low energy (BLE) beacons that operate in the IoT environment [223]. We have also noticed a tumultuous increase in media coverage of this technology as well, where research in low-power sensor technology intended for IoT-based applications is being boosted by some of the major industrial giants such as Apple, Google, Amazon, and On Semiconductor [224-233]. Statistics predict that the potential growth in this industry is exceptionally high since only $0.06 \%$ of all possible devices have been optimized for the IoT platform [234].

\subsection{Machine Learning for Nano-Biosensors}

Although there has been a significant progress in the field of nano-biosensors in the last decade, such devices still typically suffer from certain disadvantages such as electrical noise, random quantum effects, limited specificity, and reduced stability. These issues have proven to be a significant bottleneck to their successful commercialization. One of the emerging technologies which is being used to mitigate such deficiencies is machine learning. From the perspective of biosensor applications, machine learning can be broadly described as an algorithmic approach for analyzing sensor data and extracting useful information by means of statistical techniques [235]. Machine-learning techniques have been primarily used for either classification or regression analysis. Therefore, it follows naturally, that such tools are extremely useful for the field of chemometrics. Some of the primary machine-learning algorithms which are being widely used for such purposes include support-vector machine, random forest, artificial, and convolutional neural networks, Naïve Bayes, convolutional neural network, and $k$-nearest neighbor $(\mathrm{kNN})$. A more in-depth review of the various algorithms for implementing machine learning for biosensing purposes can be found here [236]. Due to their advanced pattern-recognition abilities, machine-learning algorithms can assist nano-biosensors in extracting information from raw data that would be otherwise not apparent. For example, such algorithms have been used to help classify raw sensor data and reduce the risk of cross-sensitivity and false detections. Additionally, machine-learning techniques have been used for reducing background noise from the sensor output which allows for a lower limit of detection. The following paragraph highlights some examples of biosensing technology improved by using machine-learning techniques.

Guselnikova et al. demonstrated the use of convolutional neural networks for surfaceenhanced Raman spectroscopy for detection of oligonucleotide damage on gold gratings [237]. Using binary stochastic filtering techniques, very small DNA damage was 
detected. A similar technique was used to classify between cancerous and noncancerous cell-groups using AuNPs [238]. Using neural networks, the achieved accuracy of classification was $>98 \%$. Thrift et al. demonstrated single-entity analysis by using convolutional neural network-assisted surface-enhanced Raman spectroscopy techniques for detecting ultralow (<nanomolar) concentrations of Rhodamine 800 [239]. Similarly, Lu et al. reported identifying microorganisms at single cellular level using laser tweezer spectroscopy with convolutional neural networks, with a classification accuracy of $\sim 95 \%$ [240]. Pandit et al. demonstrated highly accurate detection of proteins present in low concentrations, without the use of any bioreceptor by using carbon-dot sensors assisted by a variety of machine learning algorithms [241]. The authors also provided a comparative analysis of the accuracy achieved by different algorithms, which ranged from $83-100 \%$. Solmaz et al. demonstrated a smart-phone application which utilized machine-learning classifiers for quantifying calorimetric tests [242]. Similarly, Gunda et al. developed a smart-phone application for accurate monitoring water contaminated with certain bacteria such as Escherichia coli, by analyzing data obtained by a colorimetric biosensor [243]. Kim et al. demonstrated a smart-phone application for testing the presence of alcohol in saliva using various machine-learning algorithms such as ANN [244]. Ballard et al. demonstrated detection of C-reactive protein by using paper sensors assisted with deep-learning techniques [245]. Luo et al. made use of convolutional neural network algorithms for colorimetric sensing of organic carbon in water [246]. Gonzalez et al. provided a comparative analysis of various machine-learning algorithms for improving the accuracy of a glucose oxidase biosensor [247]. By using artificial neural networks and support-vector machine algorithms, Ali et al. demonstrated successful impedance-based classification of Escherichia coli and Salmonella typhimurium by using silver nanowires on polyimide substrates [248]. Albrecht et al. implemented deep learning techniques for the classification of various amino acids using a nanogap-based biosensor [249]. Tsutsui et al. utilized a rotation forest model for classifying Escherichia coli and Bacillus subtilis [250]. Zeng et al. demonstrated machine-learning-enabled monitoring of mental fatigue using epidermal biosensors [251]. Besides classification algorithms, machine-learning techniques have also been employed for prediction-based analysis as well. For example, Jeong et al. developed a wearable sensor for early detection of COVID19 symptoms such as high temperature, heart rate and regular coughing patterns [252]. Tatarko et al. developed a quartz crystal microbalance biosensor for accurate classification between low concentration of trypsin and plasmin [253]. Adak et al. used similar sensing techniques to classify five different alcohol analytes with the aid of an artificial bee colony algorithm [254]. Yan et al. used magnetic NPs for detection of cardiac markers and improved the performance of the nano-biosensor by using support-vector machine technique [255].

\section{Conclusions}

The advent of nanotechnology has undoubtedly aided the field of biosensors to reach new heights. Sensor parameters such as limit of detection, accuracy, and reliability have been shown to improve by incorporating nanomaterials/nanostructures for biosensing purposes. Such novel biosensors have been demonstrated to display single-molecule detection, significantly amplified transduction outputs as well as allowed rapid detection of intended analyte. These properties have helped remove certain bottlenecks which have hitherto prevented the practical implementation of biosensors. However, this technology is also plagued by certain disadvantages such as the inevitable release of nanoparticles into the environment. Additionally, although quantum effects result in very high sensitivity, they are often the source of randomized noise and background signal. Therefore, such sensors have displayed cross-sensitivity, nonlinear, and nonrepeatable response upon exposure to certain analytes. Furthermore, materials such as graphene while highly attractive for biosensing purposes have not yet been successfully mass fabricated. These limitations still need to be carefully addressed before the entire world can successfully harness the amazing properties of nanotechnology in biosensors. In conclusion, this review article aims at providing the 
reader a detailed overview of some of the most commonly used biosensors which have been realized by nanotechnology-enabled thin-films and miniaturized structures. These include thin-films, gold nanoparticles, carbon nanotubes, graphene, and quantum-dots. Numerous examples from literature have also been cited to provide the applications of such biosensors. Furthermore, the article also describes the influence of such biosensors specific to the vital field of cancer research. A future perspective with respect to low-power sensors for the Internet of things including future commercial prospects of this technology as well as the role of machine-learning techniques in biosensing has also been provided.

Author Contributions: Conceptualization, data collection and manuscript writing, A.B. and S.M.; Resources and manuscript review and editing, C.H.M. All authors have read and agreed to the published version of the manuscript.

Funding: This research received no external funding.

Conflicts of Interest: The authors declare no conflict of interest.

\section{References}

1. Pickel, D.; Manucy, G.P.; Walker, D.B.; Hall, S.B.; Walker, J.C. Evidence for Canine Olfactory Detection of Melanoma. Appl. Anim. Behav. Sci. 2004, 89, 107-116. [CrossRef]

2. Fields, R.D. The Shark's Electric Sense. Sci. Am. 2007, 297, 75-80. [CrossRef] [PubMed]

3. Telefoncu, A. Telefoncu Biochemistry Graduate Summer School-Biosensors; Ege University Science Faculty Press: Izmir, Turkey, 1999.

4. Farré, M.; Kantiani, L.; Barceló, D. Microfluidic Devices: Biosensors; Academic Press: Cambridge, CA, USA, 2012; ISBN 9780123848628. Available online: https:/ / www.sciencedirect.com/science/article/pii/B9780128132661000061 (accessed on 1 December 2020).

5. Clark, L.C.; Lyons, C. Electrode Systems for Continuous Monitoring in Cardiovascular Surgery. Ann. N. Y. Acad. Sci. 1962, 102, 29-45. [CrossRef] [PubMed]

6. Guilbault, G.G.; Montalvo, J.G. Urea-Specific Enzyme Electrode. J. Am. Chem. Soc. 1969, 91, 2164-2165. [CrossRef] [PubMed]

7. Scheller, F.W.; Schubert, F.; Neumann, B.; Pfeiffer, D.; Hintsche, R.; Dransfeld, I.; Wollenberger, U.; Renneberg, R.; Warsinke, A.; Johansson, G.; et al. Second Generation Biosensors. Biosens. Bioelectron. 1991, 6, 245-253. [CrossRef]

8. Clark, M.F.; Lister, R.M.; Bar-Joseph, M. ELISA Techniques. 1986, pp. 742-766. Available online: https://www.abcam.com/kits/ elisa-principle (accessed on 1 December 2020).

9. Homola, J.; Piliarik, M. Surface Plasmon Resonance (SPR) Sensors; Springer: Berlin/Heidelberg, Germany, 2006; pp. 45-67.

10. Cho, I.H.; Kim, D.H.; Park, S. Electrochemical Biosensors: Perspective on Functional Nanomaterials for on-Site Analysis. Biomater. Res. 2020, 24, 1-12. [CrossRef] [PubMed]

11. Rasheed, P.A.; Sandhyarani, N. Electrochemical DNA Sensors Based on the Use of Gold Nanoparticles: A Review on Recent Developments. Microchim. Acta 2017, 184, 981-1000. [CrossRef]

12. Jiang, P.; Wang, Y.; Zhao, L.; Ji, C.; Chen, D.; Nie, L. Applications of Gold Nanoparticles in Non-Optical Biosensors. Nanomaterials 2018, 8, 977. [CrossRef]

13. Pohanka, M. Overview of Piezoelectric Biosensors, Immunosensors and DNA Sensors and Their Applications. Materials 2018, 11, 448. [CrossRef]

14. Aldewachi, H.; Chalati, T.; Woodroofe, M.N.; Bricklebank, N.; Sharrack, B.; Gardiner, P. Gold Nanoparticle-Based Colorimetric Biosensors. Nanoscale 2018, 10, 18-33. [CrossRef] [PubMed]

15. Silva, T.A.; Moraes, F.C.; Janegitz, B.C.; Fatibello-Filho, O.; Ganta, D. Electrochemical Biosensors Based on Nanostructured Carbon Black: A Review. J. Nanomater. 2017, 2017. [CrossRef]

16. Kour, R.; Arya, S.; Young, S.-J.; Gupta, V.; Bandhoria, P.; Khosla, A. Review—Recent Advances in Carbon Nanomaterials as Electrochemical Biosensors. J. Electrochem. Soc. 2020, 167, 037555. [CrossRef]

17. Peña-Bahamonde, J.; Nguyen, H.N.; Fanourakis, S.K.; Rodrigues, D.F. Recent Advances in Graphene-Based Biosensor Technology with Applications in Life Sciences. J. Nanobiotechnol. 2018, 16, 1-17. [CrossRef]

18. Coroş, M.; Pruneanu, S.; Stefan-van Staden, R.-I. Review-Recent Progress in the Graphene-Based Electrochemical Sensors and Biosensors. J. Electrochem. Soc. 2020, 167, 037528. [CrossRef]

19. Merkoçi, A. Graphene-Based Biosensors. 2D Mater. 2020, 7, 040401. [CrossRef]

20. Sánchez, A.; Villalonga, A.; Martínez-García, G.; Parrado, C.; Villalonga, R. Dendrimers as Soft Nanomaterials for Electrochemical Immunosensors. Nanomaterials 2019, 9, 1745. [CrossRef] [PubMed]

21. Erdem, A.; Eksin, E.; Kesici, E.; Yarali, E. Dendrimers Integrated Biosensors for Healthcare Applications; Elsevier Inc.: Amsterdam, The Netherlands, 2018; ISBN 9780128138854.

22. Chandra, S.; Mayer, M.; Baeumner, A.J. PAMAM Dendrimers: A Multifunctional Nanomaterial for ECL Biosensors. Talanta 2017, 168, 126-129. [CrossRef]

23. Wang, N.; Hang, T.; Ling, H.; Hu, A.; Li, M. High-Performance Si-Based 3D Cu Nanostructured Electrode Assembly for Rechargeable Lithium Batteries. J. Mater. Chem. A 2015, 3, 11912-11919. [CrossRef] 
24. Weber, J.; Jeedigunta, S.; Kumar, A. Fabrication and Characterization of ZnO Nanowire Arrays with an Investigation into Electrochemical Sensing Capabilities. J. Nanomater. 2008, 2008, 1-5. [CrossRef]

25. Parikh, R.Y.; Singh, S.; Prasad, B.L.V.; Patole, M.S.; Sastry, M.; Shouche, Y.S. Extracellular Synthesis of Crystalline Silver Nanoparticles and Molecular Evidence of Silver Resistance from Morganella Sp.: Towards Understanding Biochemical Synthesis Mechanism. ChemBioChem 2008, 9, 1415-1422. [CrossRef]

26. Singh, S. Emerging Trends in Nanotechnology: Nanozymes, Imaging Probes and Biosensors and Nanocarriers. Curr. Drug Metab. 2019, 20, 414-415. [CrossRef]

27. Banerjee, A.; Khan, S.H.; Broadbent, S.; Bulbul, A.; Kim, K.H.; Looper, R.; Mastrangelo, C.H.; KIM, H. Molecular Bridge Mediated Ultra-Low-Power Gas Sensing. arXiv 2019, arXiv:1911.05965v1.

28. Sokolov, A.N.; Tee, B.C.-K.; Bettinger, C.J.; Tok, J.B.-H.; Bao, Z. Chemical and Engineering Approaches To Enable Organic Field-Effect Transistors for Electronic Skin Applications. Acc. Chem. Res. 2012, 45, 361-371. [CrossRef]

29. Xiao, Y. "Plugging into Enzymes": Nanowiring of Redox Enzymes by a Gold Nanoparticle. Science 2003, $299,1877-1881$. [CrossRef]

30. Schierhorn, M.; Lee, S.J.; Boettcher, S.W.; Stucky, G.D.; Moskovits, M. Metal-Silica Hybrid Nanostructures for Surface-Enhanced Raman Spectroscopy. Adv. Mater. 2006, 18, 2829-2832. [CrossRef]

31. Cai, H.; Xu, Y.; Zhu, N.; He, P.; Fang, Y. An Electrochemical DNA Hybridization Detection Assay Based on a Silver Nanoparticle Label. Analyst 2002, 127, 803-808. [CrossRef]

32. Luo, X.-L.; Xu, J.-J.; Zhao, W.; Chen, H.-Y. A Novel Glucose ENFET Based on the Special Reactivity of MnO2 Nanoparticles. Biosens. Bioelectron. 2004, 19, 1295-1300. [CrossRef]

33. Wang, J.; Liu, G.; Polsky, R.; Merkoçi, A. Electrochemical Stripping Detection of DNA Hybridization Based on Cadmium Sulfide Nanoparticle Tags. Electrochem. Commun. 2002, 4, 722-726. [CrossRef]

34. Huang, Y.-Y.; Tian, Y.; Liu, X.-Q.; Niu, Z.; Yang, Q.-Z.; Ramamurthy, V.; Tung, C.-H.; Chen, Y.-Z.; Wu, L.-Z. Luminescent Supramolecular Polymer Nanoparticles for Ratiometric Hypoxia Sensing, Imaging and Therapy. Mater. Chem. Front. 2018, 2, 1893-1899. [CrossRef]

35. Chakrabarty, S.; Maity, S.; Yazhini, D.; Ghosh, A. Surface-Directed Disparity in Self-Assembled Structures of Small-Peptide L-Glutathione on Gold and Silver Nanoparticles. Langmuir 2020, 36, 11255-11261. [CrossRef] [PubMed]

36. Englebienne, P. Use of Colloidal Gold Surface Plasmon Resonance Peak Shift to Infer Affinity Constants from the Interactions between Protein Antigens and Antibodies Specific for Single or Multiple Epitopes. Analyst 1998, 123, 1599-1603. [CrossRef]

37. Lin, T.-J.; Huang, K.-T.; Liu, C.-Y. Determination of Organophosphorous Pesticides by a Novel Biosensor Based on Localized Surface Plasmon Resonance. Biosens. Bioelectron. 2006, 22, 513-518. [CrossRef]

38. He, L.; Musick, M.D.; Nicewarner, S.R.; Salinas, F.G.; Benkovic, S.J.; Natan, M.J.; Keating, C.D. Colloidal Au-Enhanced Surface Plasmon Resonance for Ultrasensitive Detection of DNA Hybridization. J. Am. Chem. Soc. 2000, 122, 9071-9077. [CrossRef]

39. Li, Y.; Wark, A.W.; Lee, H.J.; Corn, R.M. Single-Nucleotide Polymorphism Genotyping by Nanoparticle-Enhanced Surface Plasmon Resonance Imaging Measurements of Surface Ligation Reactions. Anal. Chem. 2006, 78, 3158-3164. [CrossRef] [PubMed]

40. Okamoto, T.; Yamaguchi, I.; Kobayashi, T. Local Plasmon Sensor with Gold Colloid Monolayers Deposited upon Glass Substrates. Opt. Lett. 2000, 25, 372. [CrossRef] [PubMed]

41. Matsui, J.; Akamatsu, K.; Hara, N.; Miyoshi, D.; Nawafune, H.; Tamaki, K.; Sugimoto, N. SPR Sensor Chip for Detection of Small Molecules Using Molecularly Imprinted Polymer with Embedded Gold Nanoparticles. Anal. Chem. 2005, 77, 4282-4285. [CrossRef] [PubMed]

42. Qi, Z.; Honma, I.; Zhou, H. Humidity Sensor Based on Localized Surface Plasmon Resonance of Multilayer Thin Films of Gold Nanoparticles Linked with Myoglobin. Opt. Lett. 2006, 31, 1854. [CrossRef] [PubMed]

43. Tseng, Y.-T.; Chuang, Y.-J.; Wu, Y.-C.; Yang, C.-S.; Wang, M.-C.; Tseng, F.-G. A Gold-Nanoparticle-Enhanced Immune Sensor Based on Fiber Optic Interferometry. Nanotechnology 2008, 19, 345501. [CrossRef]

44. Katz, E.; Willner, I.; Wang, J. Electroanalytical and Bioelectroanalytical Systems Based on Metal and Semiconductor Nanoparticles. Electroanalysis 2004, 16, 19-44. [CrossRef]

45. Brown, K.R.; Fox, A.P.; Natan, M.J. Morphology-Dependent Electrochemistry of Cytochrome c at Au Colloid-Modified SnO 2 Electrodes. J. Am. Chem. Soc. 1996, 118, 1154-1157. [CrossRef]

46. Xu, Q.; Mao, C.; Liu, N.-N.; Zhu, J.-J.; Sheng, J. Direct Electrochemistry of Horseradish Peroxidase Based on Biocompatible Carboxymethyl Chitosan-Gold Nanoparticle Nanocomposite. Biosens. Bioelectron. 2006, 22, 768-773. [CrossRef]

47. Wu, J.; Yan, F.; Zhang, X.; Yan, Y.; Tang, J.; Ju, H. Disposable Reagentless Electrochemical Immunosensor Array Based on a Biopolymer/Sol-Gel Membrane for Simultaneous Measurement of Several Tumor Markers. Clin. Chem. 2008, 54, 1481-1488. [CrossRef]

48. Andreescu, S.; Luck, L.A. Studies of the Binding and Signaling of Surface-Immobilized Periplasmic Glucose Receptors on Gold Nanoparticles: A Glucose Biosensor Application. Anal. Biochem. 2008, 375, 282-290. [CrossRef]

49. Kang, J.; Li, X.; Wu, G.; Wang, Z.; Lu, X. A New Scheme of Hybridization Based on the Aunano-DNA Modified Glassy Carbon Electrode. Anal. Biochem. 2007, 364, 165-170. [CrossRef]

50. Cai, H.; Xu, C.; He, P.; Fang, Y. Colloid Au-Enhanced DNA Immobilization for the Electrochemical Detection of Sequence-Specific DNA. J. Electroanal. Chem. 2001, 510, 78-85. [CrossRef] 
51. Cui, R.; Huang, H.; Yin, Z.; Gao, D.; Zhu, J.-J. Horseradish Peroxidase-Functionalized Gold Nanoparticle Label for Amplified Immunoanalysis Based on Gold Nanoparticles/Carbon Nanotubes Hybrids Modified Biosensor. Biosens. Bioelectron. 2008, 23, 1666-1673. [CrossRef]

52. Turner, M.; Golovko, V.B.; Vaughan, O.P.H.; Abdulkin, P.; Berenguer-Murcia, A.; Tikhov, M.S.; Johnson, B.F.G.; Lambert, R.M. Selective Oxidation with Dioxygen by Gold Nanoparticle Catalysts Derived from 55-Atom Clusters. Nature 2008, 454, 981-983. [CrossRef]

53. Raj, C.R.; Jena, B.K. Efficient Electrocatalytic Oxidation of NADH at Gold Nanoparticles Self-Assembled on Three-Dimensional Sol-Gel Network. Chem. Commun. 2005, 2005. [CrossRef] [PubMed]

54. Bharathi, S.; Nogamia, M. A Glucose Biosensor Based on Electrodeposited Biocomposites of Gold Nanoparticles and Glucose Oxidase Enzyme. Analyst 2001. [CrossRef] [PubMed]

55. Lin, L.; Zhao, H.; Li, J.; Tang, J.; Duan, M.; Jiang, L. Study on Colloidal Au-Enhanced DNA Sensing by Quartz Crystal Microbalance. Biochem. Biophys. Res. Commun. 2000, 274, 817-820. [CrossRef]

56. Zhou, X.C.; O'Shea, S.J.; Li, S.F.Y. Amplified Microgravimetric Gene Sensor Using Au Nanoparticle Modified Oligonucleotides. Chem. Commun. 2000, 953-954. [CrossRef]

57. Pang, L.; Li, J.; Jiang, J.; Shen, G.; Yu, R. DNA Point Mutation Detection Based on DNA Ligase Reaction and Nano-Au Amplification: A Piezoelectric Approach. Anal. Biochem. 2006, 358, 99-103. [CrossRef] [PubMed]

58. Chen, S.-H.; Wu, V.C.H.; Chuang, Y.-C.; Lin, C.-S. Using Oligonucleotide-Functionalized Au Nanoparticles to Rapidly Detect Foodborne Pathogens on a Piezoelectric Biosensor. J. Microbiol. Methods 2008, 73, 7-17. [CrossRef]

59. Chu, X.; Zhao, Z.-L.; Shen, G.-L.; Yu, R.-Q. Quartz Crystal Microbalance Immunoassay with Dendritic Amplification Using Colloidal Gold Immunocomplex. Sens. Actuators B Chem. 2006, 114, 696-704. [CrossRef]

60. Ding, Y.; Liu, J.; Wang, H.; Shen, G.; Yu, R. A Piezoelectric Immunosensor for the Detection of $\alpha$-Fetoprotein Using an Interface of Gold/Hydroxyapatite Hybrid Nanomaterial. Biomaterials 2007, 28, 2147-2154. [CrossRef]

61. Lin, Z.; Wu, G.; Zhao, L.; Lai, K.W.C. Carbon Nanomaterial-Based Biosensors: A Review of Design and Applications. IEEE Nanotechnol. Mag. 2019, 13, 4-14. [CrossRef]

62. Liu, H.; Zhang, L.; Yan, M.; Yu, J. Carbon Nanostructures in Biology and Medicine. J. Mater. Chem. B 2017, 5, 6437-6450. [CrossRef]

63. Vamvakaki, V.; Chaniotakis, N. Carbon Nanostructures as Transducers in Biosensors. Sens. Actuators B Chem. 2007, 126, 193-197. [CrossRef]

64. Rasheed, P.A.; Sandhyarani, N. Carbon Nanostructures as Immobilization Platform for DNA: A Review on Current Progress in Electrochemical DNA Sensors. Biosens. Bioelectron. 2017, 97, 226-237. [CrossRef]

65. Iijima, S.; Yudasaka, M.; Yamada, R.; Bandow, S.; Suenaga, K.; Kokai, F.; Takahashi, K. Nano-Aggregates of Single-Walled Graphitic Carbon Nano-Horns. Chem. Phys. Lett. 1999, 309, 165-170. [CrossRef]

66. Wang, Z.; Dai, Z. Carbon Nanomaterial-Based Electrochemical Biosensors: An Overview. Nanoscale 2015, 7, 6420-6431. [CrossRef]

67. Patolsky, F.; Weizmann, Y.; Willner, I. Long-Range Electrical Contacting of Redox Enzymes by SWCNT Connectors. Angew. Chemie Int. Ed. 2004, 43, 2113-2117. [CrossRef]

68. Li, G.; Liao, J.M.; Hu, G.Q.; Ma, N.Z.; Wu, P.J. Study of Carbon Nanotube Modified Biosensor for Monitoring Total Cholesterol in Blood. Biosens. Bioelectron. 2005, 20, 2140-2144. [CrossRef]

69. Santos, R.M.; Rodrigues, M.S.; Laranjinha, J.; Barbosa, R.M. Biomimetic Sensor Based on Hemin/Carbon Nanotubes/Chitosan Modified Microelectrode for Nitric Oxide Measurement in the Brain. Biosens. Bioelectron. 2013, 44, 152-159. [CrossRef]

70. Prasad, B.B.; Prasad, A.; Tiwari, M.P.; Madhuri, R. Multiwalled Carbon Nanotubes Bearing 'Terminal Monomeric Unit' for the Fabrication of Epinephrine Imprinted Polymer-Based Electrochemical Sensor. Biosens. Bioelectron. 2013, 45, 114-122. [CrossRef]

71. Kress, G.J.; Shu, H.-J.; Yu, A.; Taylor, A.; Benz, A.; Harmon, S.; Mennerick, S. Fast Phasic Release Properties of Dopamine Studied with a Channel Biosensor. J. Neurosci. 2014, 34, 11792-11802. [CrossRef] [PubMed]

72. Zelada-Guillén, G.A.; Tweed-Kent, A.; Niemann, M.; Göringer, H.U.; Riu, J.; Rius, F.X. Ultrasensitive and Real-Time Detection of Proteins in Blood Using a Potentiometric Carbon-Nanotube Aptasensor. Biosens. Bioelectron. 2013, 41, 366-371. [CrossRef]

73. Zhang, J.; Boghossian, A.A.; Barone, P.W.; Rwei, A.; Kim, J.-H.; Lin, D.; Heller, D.A.; Hilmer, A.J.; Nair, N.; Reuel, N.F.; et al. Single Molecule Detection of Nitric Oxide Enabled by d(AT) 15 DNA Adsorbed to Near Infrared Fluorescent Single-Walled Carbon Nanotubes. J. Am. Chem. Soc. 2011, 133, 567-581. [CrossRef]

74. Jin, H.; Heller, D.A.; Strano, M.S. Single-Particle Tracking of Endocytosis and Exocytosis of Single-Walled Carbon Nanotubes in NIH-3T3 Cells. Nano Lett. 2008, 8, 1577-1585. [CrossRef]

75. Fei, S.; Chen, J.; Yao, S.; Deng, G.; He, D.; Kuang, Y. Electrochemical Behavior of L-Cysteine and Its Detection at Carbon Nanotube Electrode Modified with Platinum. Anal. Biochem. 2005, 339, 29-35. [CrossRef]

76. Antiochia, R.; Lavagnini, I.; Magno, F. Amperometric Mediated Carbon Nanotube Paste Biosensor for Fructose Determination. Anal. Lett. 2004, 37, 1657-1669. [CrossRef]

77. Lübbers, D.W.; Opitz, N. The $\mathrm{PCO}_{2}-/ \mathrm{PO}_{2}$-Optode: A New Probe for Measurement of $\mathrm{PCO}_{2}$ or PO in Fluids and Gases (Authors Transl). Z. Naturforsch. C Biosci. 1975, 30, 532-533. [CrossRef]

78. Kim, J.-H.; Ahn, J.-H.; Barone, P.W.; Jin, H.; Zhang, J.; Heller, D.A.; Strano, M.S. A Luciferase/Single-Walled Carbon Nanotube Conjugate for Near-Infrared Fluorescent Detection of Cellular ATP. Angew. Chem. Int. Ed. 2010, 49, 1456-1459. [CrossRef] [PubMed] 
79. Heller, D.A.; Pratt, G.W.; Zhang, J.; Nair, N.; Hansborough, A.J.; Boghossian, A.A.; Reuel, N.F.; Barone, P.W.; Strano, M.S. Peptide Secondary Structure Modulates Single-Walled Carbon Nanotube Fluorescence as a Chaperone Sensor for Nitroaromatics. Proc. Natl. Acad. Sci. USA 2011, 108, 8544-8549. [CrossRef]

80. Yi, H.; Ghosh, D.; Ham, M.-H.; Qi, J.; Barone, P.W.; Strano, M.S.; Belcher, A.M. M13 Phage-Functionalized Single-Walled Carbon Nanotubes As Nanoprobes for Second Near-Infrared Window Fluorescence Imaging of Targeted Tumors. Nano Lett. 2012, 12, 1176-1183. [CrossRef]

81. Yang, S.; Fernando, K.A.S.; Liu, J.; Wang, J.; Sun, H.; Liu, Y.; Chen, M.; Huang, Y.; Wang, X.; Wang, H.; et al. Covalently PEGylated Carbon Nanotubes with Stealth Character In Vivo. Small 2008, 4, 940-944. [CrossRef] [PubMed]

82. Zhang, J.; Kruss, S.; Hilmer, A.J.; Shimizu, S.; Schmois, Z.; De La Cruz, F.; Barone, P.W.; Reuel, N.F.; Heller, D.A.; Strano, M.S. A Rapid, Direct, Quantitative, and Label-Free Detector of Cardiac Biomarker Troponin T Using Near-Infrared Fluorescent Single-Walled Carbon Nanotube Sensors. Adv. Healthc. Mater. 2014, 3, 412-423. [CrossRef]

83. Zhang, J.; Landry, M.P.; Barone, P.W.; Kim, J.-H.; Lin, S.; Ulissi, Z.W.; Lin, D.; Mu, B.; Boghossian, A.A.; Hilmer, A.J.; et al. Molecular Recognition Using Corona Phase Complexes Made of Synthetic Polymers Adsorbed on Carbon Nanotubes. Nat. Nanotechnol. 2013, 8, 959-968. [CrossRef] [PubMed]

84. Wallace, P.R. The Band Theory of Graphite. Phys. Rev. 1947, 71, 622-634. [CrossRef]

85. Novoselov, K.S. Electric Field Effect in Atomically Thin Carbon Films. Science 2004, 306, 666-669. [CrossRef]

86. Wei, Y.; Yang, R.; Yu, X.-Y.; Wang, L.; Liu, J.-H.; Huang, X.-J. Stripping Voltammetry Study of Ultra-Trace Toxic Metal Ions on Highly Selectively Adsorptive Porous Magnesium Oxide Nanoflowers. Analyst 2012, 137, 2183. [CrossRef]

87. Kong, N.; Liu, J.; Kong, Q.; Wang, R.; Barrow, C.J.; Yang, W. Graphene Modified Gold Electrode via $\pi-\pi$ Stacking Interaction for Analysis of $\mathrm{Cu}^{2+}$ and $\mathrm{Pb}^{2+}$. Sens. Actuators B Chem. 2013, 178, 426-433. [CrossRef]

88. Zhou, C.; Jiang, W.; Via, B.K. Facile Synthesis of Soluble Graphene Quantum Dots and Its Improved Property in Detecting Heavy Metal Ions. Colloids Surf. B Biointerfaces 2014, 118, 72-76. [CrossRef] [PubMed]

89. An, J.H.; Park, S.J.; Kwon, O.S.; Bae, J.; Jang, J. High-Performance Flexible Graphene Aptasensor for Mercury Detection in Mussels. ACS Nano 2013, 7, 10563-10571. [CrossRef] [PubMed]

90. Yuan, Y.; Zhang, G.; Li, Y.; Zhang, G.; Zhang, F.; Fan, X. Poly(Amidoamine) Modified Graphene Oxide as an Efficient Adsorbent for Heavy Metal Ions. Polym. Chem. 2013, 4, 2164. [CrossRef]

91. Fan, H.; Li, Y.; Wu, D.; Ma, H.; Mao, K.; Fan, D.; Du, B.; Li, H.; Wei, Q. Electrochemical Bisphenol A Sensor Based on N-Doped Graphene Sheets. Anal. Chim. Acta 2012, 711, 24-28. [CrossRef]

92. Qu, Y.; Ma, M.; Wang, Z.; Zhan, G.; Li, B.; Wanga, X.; Fang, H.; Zhang, H.; Li, C. Sensitive Amperometric Biosensor for Phenolic Compounds Based on Graphene-Silk Peptide/Tyrosinase Composite Nanointerface. Biosens. Bioelectron. 2013, 44, 85-88. [CrossRef]

93. Zaijun, L.; Xiulan, S.; Qianfang, X.; Ruiyi, L.; Yinjun, F.; Shuping, Y.; Junkang, L. Green and Controllable Strategy to Fabricate Well-Dispersed Graphene-Gold Nanocomposite Film as Sensing Materials for the Detection of Hydroquinone and Resorcinol with Electrodeposition. Electrochim. Acta 2012, 85, 42-48. [CrossRef]

94. Liu, F.; Piao, Y.; Choi, J.S.; Seo, T.S. Three-Dimensional Graphene Micropillar Based Electrochemical Sensor for Phenol Detection. Biosens. Bioelectron. 2013, 50, 387-392. [CrossRef] [PubMed]

95. Wei, M.; Tian, D.; Liu, S.; Zheng, X.; Duan, S.; Zhou, C. $\beta$-Cyclodextrin Functionalized Graphene Material: A Novel Electrochemical Sensor for Simultaneous Determination of 2-Chlorophenol and 3-Chlorophenol. Sens. Actuators B Chem. 2014, 195, 452-458. [CrossRef]

96. Andreescu, S.; Marty, J.-L. Twenty Years Research in Cholinesterase Biosensors: From Basic Research to Practical Applications. Biomol. Eng. 2006, 23, 1-15. [CrossRef] [PubMed]

97. Hummers, W.S.; Offeman, R.E. Preparation of Graphitic Oxide. J. Am. Chem. Soc. 1958, 80, 1339. [CrossRef]

98. Choi, B.G.; Park, H.; Park, T.J.; Yang, M.H.; Kim, J.S.; Jang, S.-Y.; Heo, N.S.; Lee, S.Y.; Kong, J.; Hong, W.H. Solution Chemistry of Self-Assembled Graphene Nanohybrids for High-Performance Flexible Biosensors. ACS Nano 2010, 4, 2910-2918. [CrossRef] [PubMed]

99. Chen, M.; Meng, Y.; Zhang, W.; Zhou, J.; Xie, J.; Diao, G. $\beta$-Cyclodextrin Polymer Functionalized Reduced-Graphene Oxide: Application for Electrochemical Determination Imidacloprid. Electrochim. Acta 2013, 108, 1-9. [CrossRef]

100. Chai, Y.; Niu, X.; Chen, C.; Zhao, H.; Lan, M. Carbamate Insecticide Sensing Based on Acetylcholinesterase/Prussian Blue-MultiWalled Carbon Nanotubes/Screen-Printed Electrodes. Anal. Lett. 2013, 46, 803-817. [CrossRef]

101. Wang, M.; Huang, J.; Wang, M.; Zhang, D.; Chen, J. Electrochemical Nonenzymatic Sensor Based on CoO Decorated Reduced Graphene Oxide for the Simultaneous Determination of Carbofuran and Carbaryl in Fruits and Vegetables. Food Chem. 2014, 151, 191-197. [CrossRef]

102. Zhou, Y.; Liu, S.; Jiang, H.-J.; Yang, H.; Chen, H.-Y. Direct Electrochemistry and Bioelectrocatalysis of Microperoxidase-11 Immobilized on Chitosan-Graphene Nanocomposite. Electroanalysis 2010, 22, 1323-1328. [CrossRef]

103. Song, H.; Ni, Y.; Kokot, S. Investigations of an Electrochemical Platform Based on the Layered MoS2-Graphene and Horseradish Peroxidase Nanocomposite for Direct Electrochemistry and Electrocatalysis. Biosens. Bioelectron. 2014, 56, 137-143. [CrossRef]

104. Mannoor, M.S.; Tao, H.; Clayton, J.D.; Sengupta, A.; Kaplan, D.L.; Naik, R.R.; Verma, N.; Omenetto, F.G.; McAlpine, M.C. Graphene-Based Wireless Bacteria Detection on Tooth Enamel. Nat. Commun. 2012, 3, 763. [CrossRef] 
105. Huang, Y.; Dong, X.; Liu, Y.; Li, L.-J.; Chen, P. Graphene-Based Biosensors for Detection of Bacteria and Their Metabolic Activities. J. Mater. Chem. 2011, 21, 12358. [CrossRef]

106. Jia, F.; Duan, N.; Wu, S.; Ma, X.; Xia, Y.; Wang, Z.; Wei, X. Impedimetric Aptasensor for Staphylococcus Aureus Based on Nanocomposite Prepared from Reduced Graphene Oxide and Gold Nanoparticles. Microchim. Acta 2014, 181, 967-974. [CrossRef]

107. Bruchez, M., Jr. Semiconductor Nanocrystals as Fluorescent Biological Labels. Science 1998, 281, 2013-2016. [CrossRef]

108. Chan, W.C. Quantum Dot Bioconjugates for Ultrasensitive Nonisotopic Detection. Science 1998, 281, 2016-2018. [CrossRef] [PubMed]

109. Zhou, J.; Wang, Q.; Zhang, C. Liposome-Quantum Dot Complexes Enable Multiplexed Detection of Attomolar DNAs without Target Amplification. J. Am. Chem. Soc. 2013, 135, 2056-2059. [CrossRef]

110. Shanehsaz, M.; Mohsenifar, A.; Hasannia, S.; Pirooznia, N.; Samaei, Y.; Shamsipur, M. Detection of Helicobacter Pylori with a Nanobiosensor Based on Fluorescence Resonance Energy Transfer Using CdTe Quantum Dots. Microchim. Acta 2013, 180, 195-202. [CrossRef]

111. Noor, M.O.; Shahmuradyan, A.; Krull, U.J. Paper-Based Solid-Phase Nucleic Acid Hybridization Assay Using Immobilized Quantum Dots as Donors in Fluorescence Resonance Energy Transfer. Anal. Chem. 2013, 85, 1860-1867. [CrossRef]

112. Wang, Z.; Wang, L.; Zhang, Q.; Tang, B.; Zhang, C. Single Quantum Dot-Based Nanosensor for Sensitive Detection of 5Methylcytosine at Both CpG and Non-CpG Sites. Chem. Sci. 2018, 9, 1330-1338. [CrossRef]

113. Qiu, X.; Hildebrandt, N. Rapid and Multiplexed MicroRNA Diagnostic Assay Using Quantum Dot-Based Förster Resonance Energy Transfer. ACS Nano 2015, 9, 8449-8457. [CrossRef] [PubMed]

114. Hu, J.; Liu, M.; Zhang, C. Integration of Isothermal Amplification with Quantum Dot-Based Fluorescence Resonance Energy Transfer for Simultaneous Detection of Multiple MicroRNAs. Chem. Sci. 2018, 9, 4258-4267. [CrossRef]

115. Jou, A.F.; Lu, C.-H.; Ou, Y.-C.; Wang, S.-S.; Hsu, S.-L.; Willner, I.; Ho, J.A. Diagnosing the MiR-141 Prostate Cancer Biomarker Using Nucleic Acid-Functionalized CdSe/ZnS QDs and Telomerase. Chem. Sci. 2015, 6, 659-665. [CrossRef]

116. Su, S.; Fan, J.; Xue, B.; Yuwen, L.; Liu, X.; Pan, D.; Fan, C.; Wang, L. DNA-Conjugated Quantum Dot Nanoprobe for HighSensitivity Fluorescent Detection of DNA and Micro-RNA. ACS Appl. Mater. Interfaces 2014, 6, 1152-1157. [CrossRef]

117. Sang, L.-J.; Wang, H.-F. Aminophenylboronic-Acid-Conjugated Polyacrylic Acid-Mn-Doped ZnS Quantum Dot for Highly Sensitive Discrimination of Glycoproteins. Anal. Chem. 2014, 86, 5706-5712. [CrossRef] [PubMed]

118. Wegner, K.D.; Jin, Z.; Lindén, S.; Jennings, T.L.; Hildebrandt, N. Quantum-Dot-Based Förster Resonance Energy Transfer Immunoassay for Sensitive Clinical Diagnostics of Low-Volume Serum Samples. ACS Nano 2013, 7, 7411-7419. [CrossRef] [PubMed]

119. Qiu, Z.; Shu, J.; Tang, D. Bioresponsive Release System for Visual Fluorescence Detection of Carcinoembryonic Antigen from Mesoporous Silica Nanocontainers Mediated Optical Color on Quantum Dot-Enzyme-Impregnated Paper. Anal. Chem. 2017, 89, 5152-5160. [CrossRef] [PubMed]

120. Xu, Q.; Zhang, Y.; Tang, B.; Zhang, C. Multicolor Quantum Dot-Based Chemical Nose for Rapid and Array-Free Differentiation of Multiple Proteins. Anal. Chem. 2016, 88, 2051-2058. [CrossRef] [PubMed]

121. Park, J.; Park, Y.; Kim, S. Signal Amplification via Biological Self-Assembly of Surface-Engineered Quantum Dots for Multiplexed Subattomolar Immunoassays and Apoptosis Imaging. ACS Nano 2013, 7, 9416-9427. [CrossRef]

122. Tyrakowski, C.M.; Snee, P.T. Ratiometric CdSe/ZnS Quantum Dot Protein Sensor. Anal. Chem. 2014, 86, 2380-2386. [CrossRef]

123. Li, J.; Li, X.; Shi, X.; He, X.; Wei, W.; Ma, N.; Chen, H. Highly Sensitive Detection of Caspase-3 Activities via a Nonconjugated Gold Nanoparticle-Quantum Dot Pair Mediated by an Inner-Filter Effect. ACS Appl. Mater. Interfaces 2013, 5, 9798-9802. [CrossRef]

124. Ma, F.; Liu, W.; Tang, B.; Zhang, C. A Single Quantum Dot-Based Nanosensor for the Signal-on Detection of DNA Methyltransferase. Chem. Commun. 2017, 53, 6868-6871. [CrossRef]

125. Petryayeva, E.; Algar, W.R. Proteolytic Assays on Quantum-Dot-Modified Paper Substrates Using Simple Optical Readout Platforms. Anal. Chem. 2013, 85, 8817-8825. [CrossRef]

126. Tedsana, W.; Tuntulani, T.; Ngeontae, W. A Highly Selective Turn-on ATP Fluorescence Sensor Based on Unmodified Cysteamine Capped CdS Quantum Dots. Anal. Chim. Acta 2013, 783, 65-73. [CrossRef]

127. Yu, X.; Wen, K.; Wang, Z.; Zhang, X.; Li, C.; Zhang, S.; Shen, J. General Bioluminescence Resonance Energy Transfer Homogeneous Immunoassay for Small Molecules Based on Quantum Dots. Anal. Chem. 2016, 88, 3512-3520. [CrossRef]

128. Tsuboi, S.; Jin, T. Bioluminescence Resonance Energy Transfer (BRET)-Coupled Annexin V-Functionalized Quantum Dots for Near-Infrared Optical Detection of Apoptotic Cells. ChemBioChem 2017, 18, 2231-2235. [CrossRef] [PubMed]

129. Deng, S.; Lei, J.; Huang, Y.; Cheng, Y.; Ju, H. Electrochemiluminescent Quenching of Quantum Dots for Ultrasensitive Immunoassay through Oxygen Reduction Catalyzed by Nitrogen-Doped Graphene-Supported Hemin. Anal. Chem. 2013, 85, 5390-5396. [CrossRef] [PubMed]

130. Zhao, P.; Zhou, L.; Nie, Z.; Xu, X.; Li, W.; Huang, Y.; He, K.; Yao, S. Versatile Electrochemiluminescent Biosensor for ProteinNucleic Acid Interaction Based on the Unique Quenching Effect of Deoxyguanosine-5'-Phosphate on Electrochemiluminescence of CdTe/ZnS Quantum Dots. Anal. Chem. 2013, 85, 6279-6286. [CrossRef] [PubMed]

131. Liu, S.; Zhang, X.; Yu, Y.; Zou, G. A Monochromatic Electrochemiluminescence Sensing Strategy for Dopamine with DualStabilizers-Capped CdSe Quantum Dots as Emitters. Anal. Chem. 2014, 86, 2784-2788. [CrossRef]

132. Wang, W.; Hao, Q.; Wang, W.; Bao, L.; Lei, J.; Wang, Q.; Ju, H. Quantum Dot-Functionalized Porous ZnO Nanosheets as a Visible Light Induced Photoelectrochemical Platform for DNA Detection. Nanoscale 2014, 6, 2710-2717. [CrossRef] [PubMed] 
133. Fan, G.-C.; Han, L.; Zhang, J.-R.; Zhu, J.-J. Enhanced Photoelectrochemical Strategy for Ultrasensitive DNA Detection Based on Two Different Sizes of CdTe Quantum Dots Cosensitized $\mathrm{TiO}_{2} / \mathrm{CdS}: \mathrm{Mn}$ Hybrid Structure. Anal. Chem. 2014, 86, 10877-10884. [CrossRef]

134. Zeng, X.; Ma, S.; Bao, J.; Tu, W.; Dai, Z. Using Graphene-Based Plasmonic Nanocomposites to Quench Energy from Quantum Dots for Signal-On Photoelectrochemical Aptasensing. Anal. Chem. 2013, 85, 11720-11724. [CrossRef]

135. Feng, Q.-M.; Pan, J.-B.; Zhang, H.-R.; Xu, J.-J.; Chen, H.-Y. Disposable Paper-Based Bipolar Electrode for Sensitive Electrochemiluminescence Detection of a Cancer Biomarker. Chem. Commun. 2014, 50, 10949. [CrossRef]

136. Baj-Rossi, C.; De Micheli, G.; Carrara, S. Electrochemical Detection of Anti-Breast-Cancer Agents in Human Serum by Cytochrome P450-Coated Carbon Nanotubes. Sensors 2012, 12, 6520-6537. [CrossRef] [PubMed]

137. Ovádeková, R.; Jantová, S.; Letašiová, S.; Štepánek, I.; Labuda, J. Nanostructured Electrochemical DNA Biosensors for Detection of the Effect of Berberine on DNA from Cancer Cells. Anal. Bioanal. Chem. 2006, 386, 2055-2062. [CrossRef]

138. Liu, F.L.; Xiao, P.; Fang, H.L.; Dai, H.F.; Qiao, L.; Zhang, Y.H. Single-Walled Carbon Nanotube-Based Biosensors for the Detection of Volatile Organic Compounds of Lung Cancer. Phys. E Low-Dimens. Syst. Nanostruct. 2011, 44, 367-372. [CrossRef]

139. Park, Y.K.; Bold, B.; Lee, W.K.; Jeon, M.H.; An, K.H.; Jeong, S.Y.; Shim, Y.K. D-(+)-Galactose-Conjugated Single-Walled Carbon Nanotubes as New Chemical Probes for Electrochemical Biosensors for the Cancer Marker Galectin-3. Int. J. Mol. Sci. 2011, 12, 2946-2957. [CrossRef]

140. Zheng, T.-T.; Zhang, R.; Zou, L.; Zhu, J.-J. A Label-Free Cytosensor for the Enhanced Electrochemical Detection of Cancer Cells Using Polydopamine-Coated Carbon Nanotubes. Analyst 2012, 137, 1316-1318. [CrossRef]

141. Fayazfar, H.; Afshar, A.; Dolati, M.; Dolati, A. DNA Impedance Biosensor for Detection of Cancer, TP53 Gene Mutation, Based on Gold Nanoparticles/Aligned Carbon Nanotubes Modified Electrode. Anal. Chim. Acta 2014, 836, 34-44. [CrossRef] [PubMed]

142. Shobha, B.N.; Muniraj, N.J.R. Design, Modeling and Performance Analysis of Carbon Nanotube with DNA Strands as Biosensor for Prostate Cancer. Microsyst. Technol. 2015, 21, 791-800. [CrossRef]

143. Lerner, M.B.; D’Souza, J.; Pazina, T.; Dailey, J.; Goldsmith, B.R.; Robinson, M.K.; Johnson, A.T.C. Hybrids of a Genetically Engineered Antibody and a Carbon Nanotube Transistor for Detection of Prostate Cancer Biomarkers. ACS Nano 2012, 6, 5143-5149. [CrossRef]

144. Abdolahad, M.; Janmaleki, M.; Taghinejad, M.; Taghnejad, H.; Salehi, F.; Mohajerzadeh, S. Single-Cell Resolution Diagnosis of Cancer Cells by Carbon Nanotube Electrical Spectroscopy. Nanoscale 2013, 5, 3421. [CrossRef]

145. Liu, Y.; Zhu, F.; Dan, W.; Fu, Y.; Liu, S. Construction of Carbon Nanotube Based Nanoarchitectures for Selective Impedimetric Detection of Cancer Cells in Whole Blood. Analyst 2014, 139, 5086-5092. [CrossRef]

146. Veetil, J.V.; Ye, K. Development of Immunosensors Using Carbon Nanotubes. Biotechnol. Prog. 2008, 23, 517-531. [CrossRef]

147. Malhotra, R.; Patel, V.; Vaqué, J.P.; Gutkind, J.S.; Rusling, J.F. Ultrasensitive Electrochemical Immunosensor for Oral Cancer Biomarker IL-6 Using Carbon Nanotube Forest Electrodes and Multilabel Amplification. Anal. Chem. 2010, 82, 3118-3123. [CrossRef]

148. Wan, Y.; Deng, W.; Su, Y.; Zhu, X.; Peng, C.; Hu, H.; Peng, H.; Song, S.; Fan, C. Carbon Nanotube-Based Ultrasensitive Multiplexing Electrochemical Immunosensor for Cancer Biomarkers. Biosens. Bioelectron. 2011, 30, 93-99. [CrossRef]

149. Arkan, E.; Saber, R.; Karimi, Z.; Shamsipur, M. A Novel Antibody-Antigen Based Impedimetric Immunosensor for Low Level Detection of HER2 in Serum Samples of Breast Cancer Patients via Modification of a Gold Nanoparticles Decorated Multiwall Carbon Nanotube-Ionic Liquid Electrode. Anal. Chim. Acta 2015, 874, 66-74. [CrossRef]

150. De la Zerda, A.; Liu, Z.; Bodapati, S.; Teed, R.; Vaithilingam, S.; Khuri-Yakub, B.T.; Chen, X.; Dai, H.; Gambhir, S.S. Ultrahigh Sensitivity Carbon Nanotube Agents for Photoacoustic Molecular Imaging in Living Mice. Nano Lett. 2010, 10, $2168-2172$. [CrossRef]

151. Wang, X.; Wang, C.; Qu, K.; Song, Y.; Ren, J.; Miyoshi, D.; Sugimoto, N.; Qu, X. Ultrasensitive and Selective Detection of a Prognostic Indicator in Early-Stage Cancer Using Graphene Oxide and Carbon Nanotubes. Adv. Funct. Mater. 2010, 20, 3967-3971. [CrossRef]

152. Wang, L.-J.; Luo, M.-L.; Zhang, Q.; Tang, B.; Zhang, C.-Y. Single Quantum Dot-Based Nanosensor for Rapid and Sensitive Detection of Terminal Deoxynucleotidyl Transferase. Chem. Commun. 2017, 53, 11016-11019. [CrossRef] [PubMed]

153. Jeong, S.; Song, J.; Lee, W.; Ryu, Y.M.; Jung, Y.; Kim, S.-Y.; Kim, K.; Hong, S.C.; Myung, S.J.; Kim, S. Cancer-MicroenvironmentSensitive Activatable Quantum Dot Probe in the Second Near-Infrared Window. Nano Lett. 2017, 17, 1378-1386. [CrossRef] [PubMed]

154. Jie, G.; Zhao, Y.; Niu, S. Amplified Electrochemiluminescence Detection of Cancer Cells Using a New Bifunctional Quantum Dot as Signal Probe. Biosens. Bioelectron. 2013, 50, 368-372. [CrossRef] [PubMed]

155. Uludag, Y.; Tothill, I.E. Cancer Biomarker Detection in Serum Samples Using Surface Plasmon Resonance and Quartz Crystal Microbalance Sensors with Nanoparticle Signal Amplification. Anal. Chem. 2012, 84, 5898-5904. [CrossRef]

156. Altintas, Z.; Uludag, Y.; Gurbuz, Y.; Tothill, I.E. Surface Plasmon Resonance Based Immunosensor for the Detection of the Cancer Biomarker Carcinoembryonic Antigen. Talanta 2011, 86, 377-383. [CrossRef]

157. Ertürk, G.; Özen, H.; Tümer, M.A.; Mattiasson, B.; Denizli, A. Microcontact Imprinting Based Surface Plasmon Resonance (SPR) Biosensor for Real-Time and Ultrasensitive Detection of Prostate Specific Antigen (PSA) from Clinical Samples. Sens. Actuators B Chem. 2016, 224, 823-832. [CrossRef] 
158. Homola, J. (Ed.) Surface Plasmon Resonance Based Sensors; Springer Series on Chemical Sensors and Biosensors; Springer: Berlin/Heidelberg, Germany, 2006; Volume 4, ISBN 978-3-540-33918-2.

159. Yang, M.; Yi, X.; Wang, J.; Zhou, F. Electroanalytical and Surface Plasmon Resonance Sensors for Detection of Breast Cancer and Alzheimer's Disease Biomarkers in Cells and Body Fluids. Analyst 2014, 139, 1814. [CrossRef]

160. Chen Yong Kah, J.; Wei Kho, K.; Guat Leng Lee, C.; James Richard Sheppard, C.; Xiang Shen, Z.; Chee Soo, K.; Carolene Olivo, M. Early Diagnosis of Oral Cancer Based on the Surface Plasmon Resonance of Gold Nanoparticles. Int. J. Nanomed. 2007, 2, 785-798.

161. Law, W.-C.; Yong, K.-T.; Baev, A.; Prasad, P.N. Sensitivity Improved Surface Plasmon Resonance Biosensor for Cancer Biomarker Detection Based on Plasmonic Enhancement. ACS Nano 2011, 5, 4858-4864. [CrossRef]

162. Li, Y.; Lee, H.J.; Corn, R.M. Detection of Protein Biomarkers Using RNA Aptamer Microarrays and Enzymatically Amplified Surface Plasmon Resonance Imaging. Anal. Chem. 2007, 79, 1082-1088. [CrossRef]

163. Jang, H.S.; Park, K.N.; Kang, C.D.; Kim, J.P.; Sim, S.J.; Lee, K.S. Optical Fiber SPR Biosensor with Sandwich Assay for the Detection of Prostate Specific Antigen. Opt. Commun. 2009, 282, 2827-2830. [CrossRef]

164. Krishnan, S.; Mani, V.; Wasalathanthri, D.; Kumar, C.V.; Rusling, J.F. Attomolar Detection of a Cancer Biomarker Protein in Serum by Surface Plasmon Resonance Using Superparamagnetic Particle Labels. Angew. Chemie Int. Ed. 2011, 50, 1175-1178. [CrossRef] [PubMed]

165. Treviño, J.; Calle, A.; Rodríguez-Frade, J.M.; Mellado, M.; Lechuga, L.M. Surface Plasmon Resonance Immunoassay Analysis of Pituitary Hormones in Urine and Serum Samples. Clin. Chim. Acta 2009, 403, 56-62. [CrossRef]

166. Uludağ, Y.; Tothill, I.E. Development of a Sensitive Detection Method of Cancer Biomarkers in Human Serum (75\%) Using a Quartz Crystal Microbalance Sensor and Nanoparticles Amplification System. Talanta 2010, 82, 277-282. [CrossRef] [PubMed]

167. Formisano, N.; Jolly, P.; Bhalla, N.; Cromhout, M.; Flanagan, S.P.; Fogel, R.; Limson, J.L.; Estrela, P. Optimisation of an Electrochemical Impedance Spectroscopy Aptasensor by Exploiting Quartz Crystal Microbalance with Dissipation Signals. Sens. Actuators B Chem. 2015, 220, 369-375. [CrossRef]

168. Wang, D.; Tang, W.; Wu, X.; Wang, X.; Chen, G.; Chen, Q.; Li, N.; Liu, F. Highly Selective Detection of Single-Nucleotide Polymorphisms Using a Quartz Crystal Microbalance Biosensor Based on the Toehold-Mediated Strand Displacement Reaction. Anal. Chem. 2012, 84, 7008-7014. [CrossRef]

169. Li, S.; Li, X.; Zhang, J.; Zhang, Y.; Han, J.; Jiang, L. Quantitative Investigation of the Influence of Gold Nanoparticles on the Dynamics of DNA Hybridization Using a Programmed Multi-Channel Quartz Crystal Microbalance System. Colloids Surf. A Physicochem. Eng. Asp. 2010, 364, 158-162. [CrossRef]

170. Atay, S.; Pişkin, K.; Yılmaz, F.; Çakır, C.; Yavuz, H.; Denizli, A. Quartz Crystal Microbalance Based Biosensors for Detecting Highly Metastatic Breast Cancer Cells via Their Transferrin Receptors. Anal. Methods 2016, 8, 153-161. [CrossRef]

171. Kumar, M.; Yigit, M.; Dai, G.; Moore, A.; Medarova, Z. Image-Guided Breast Tumor Therapy Using a Small Interfering RNA Nanodrug. Cancer Res. 2010, 70, 7553-7561. [CrossRef] [PubMed]

172. Kohler, N.; Fryxell, G.E.; Zhang, M. A Bifunctional Poly(Ethylene Glycol) Silane Immobilized on Metallic Oxide-Based Nanoparticles for Conjugation with Cell Targeting Agents. J. Am. Chem. Soc. 2004, 126, 7206-7211. [CrossRef]

173. Chen, F.-H.; Zhang, L.-M.; Chen, Q.-T.; Zhang, Y.; Zhang, Z.-J. Synthesis of a Novel Magnetic Drug Delivery System Composed of Doxorubicin-Conjugated $\mathrm{Fe}_{3} \mathrm{O}_{4}$ Nanoparticle Cores and a PEG-Functionalized Porous Silica Shell. Chem. Commun. 2010, 46, 8633. [CrossRef] [PubMed]

174. Lim, E.-K.; Huh, Y.-M.; Yang, J.; Lee, K.; Suh, J.-S.; Haam, S. PH-Triggered Drug-Releasing Magnetic Nanoparticles for Cancer Therapy Guided by Molecular Imaging by MRI. Adv. Mater. 2011, 23, 2436-2442. [CrossRef] [PubMed]

175. Bakandritsos, A.; Mattheolabakis, G.; Chatzikyriakos, G.; Szabo, T.; Tzitzios, V.; Kouzoudis, D.; Couris, S.; Avgoustakis, K. Doxorubicin Nanocarriers Based on Magnetic Colloids with a Bio-Polyelectrolyte Corona and High Non-Linear Optical Response: Synthesis, Characterization, and Properties. Adv. Funct. Mater. 2011, 21, 1465-1475. [CrossRef]

176. Santra, S.; Kaittanis, C.; Grimm, J.; Perez, J.M. Drug/Dye-Loaded, Multifunctional Iron Oxide Nanoparticles for Combined Targeted Cancer Therapy and Dual Optical/Magnetic Resonance Imaging. Small 2009, 5, 1862-1868. [CrossRef]

177. Hwu, J.R.; Lin, Y.S.; Josephrajan, T.; Hsu, M.-H.; Cheng, F.-Y.; Yeh, C.-S.; Su, W.-C.; Shieh, D.-B. Targeted Paclitaxel by Conjugation to Iron Oxide and Gold Nanoparticles. J. Am. Chem. Soc. 2009, 131, 66-68. [CrossRef]

178. Gupta, A.K.; Gupta, M. Synthesis and Surface Engineering of Iron Oxide Nanoparticles for Biomedical Applications. Biomaterials 2005, 26, 3995-4021. [CrossRef] [PubMed]

179. Lee, Y.; Lee, J.; Bae, C.J.; Park, J.-G.; Noh, H.-J.; Park, J.-H.; Hyeon, T. Large-Scale Synthesis of Uniform and Crystalline Magnetite Nanoparticles Using Reverse Micelles as Nanoreactors under Reflux Conditions. Adv. Funct. Mater. 2005, 15, 503-509. [CrossRef]

180. Hyeon, T.; Lee, S.S.; Park, J.; Chung, Y.; Na, H. Bin Synthesis of Highly Crystalline and Monodisperse Maghemite Nanocrystallites without a Size-Selection Process. J. Am. Chem. Soc. 2001, 123, 12798-12801. [CrossRef]

181. Carta, D.; Casula, M.F.; Floris, P.; Falqui, A.; Mountjoy, G.; Boni, A.; Sangregorio, C.; Corrias, A. Synthesis and Microstructure of Manganese Ferrite Colloidal Nanocrystals. Phys. Chem. Chem. Phys. 2010, 12, 5074. [CrossRef] [PubMed]

182. Chikkadi, K.; Muoth, M.; Maiwald, V.; Roman, C.; Hierold, C. Ultra-Low Power Operation of Self-Heated, Suspended Carbon Nanotube Gas Sensors. Appl. Phys. Lett. 2013, 103. [CrossRef]

183. Ngoc, T.M.; Nguyen, H.; Hung, C.M.; Trung, N.N.; Van Duy, N. $\mathrm{H}_{2} \mathrm{~S}$ Sensing Characteristics of Self-Heated Ag-Coated SnO 2 Nanowires $\mathrm{H}_{2} \mathrm{~S}$ Sensing Characteristics of Self-Heated Ag-Coated $\mathrm{SnO}_{2}$ Nanowires. In Proceedings of the The 12th Asian Conference on Chemical Sensors (ACCS2017), Hanoi, Vietnam, 12-15 November 2017; pp. 1-5. 
184. Wang, B.; Zhu, L.F.; Yang, Y.H.; Xu, N.S.; Yang, G.W. Fabrication of a SnO2 Nanowire Gas Sensor and Sensor Performance for Hydrogen. J. Phys. Chem. C 2008, 112, 6643-6647. [CrossRef]

185. Liu, D.; Lin, L.; Chen, Q.; Zhou, H.; Wu, J. Low Power Consumption Gas Sensor Created from Silicon Nanowires/TiO2 Core-Shell Heterojunctions. ACS Sens. 2017, 2, 1491-1497. [CrossRef]

186. Han, J.W.; Rim, T.; Baek, C.K.; Meyyappan, M. Chemical Gated Field Effect Transistor by Hybrid Integration of One-Dimensional Silicon Nanowire and Two-Dimensional Tin Oxide Thin Film for Low Power Gas Sensor. ACS Appl. Mater. Interfaces 2015, 7, 21263-21269. [CrossRef]

187. Cho, M.; Yun, J.; Kwon, D.; Kim, K.; Park, I. High-Sensitivity and Low-Power Flexible Schottky Hydrogen Sensor Based on Silicon Nanomembrane. ACS Appl. Mater. Interfaces 2018, 10, 12870-12877. [CrossRef]

188. Alreshaid, A.T.; Hester, J.G.; Su, W.; Fang, Y.; Tentzeris, M.M. Review-Ink-Jet Printed Wireless Liquid and Gas Sensors for IoT, SmartAg and Smart City Applications. J. Electrochem. Soc. 2018, 165, B407-B413. [CrossRef]

189. Stetter, J.R.; Carter, M.T. High Volume Zero Power Low Cost PPB Level Printed Nano-Sensors for IoT. ECS Trans. 2017, 77, 1825-1832. [CrossRef]

190. Al Mamun, M.A.; Yuce, M.R. Sensors and Systems for Wearable Environmental Monitoring Toward IoT-Enabled Applications: A Review. IEEE Sens. J. 2019, 19, 7771-7788. [CrossRef]

191. Long, H.; Turner, S.; Yan, A.; Xu, H.; Jang, M.; Carraro, C.; Maboudian, R.; Zettl, A. Plasma Assisted Formation of 3D Highly Porous Nanostructured Metal Oxide Network on Microheater Platform for Low Power Gas Sensing. Sens. Actuators B Chem. 2019, 301, 127067. [CrossRef]

192. Eyal Weiss, R.A. Low-Power and High-Sensitivity Magnetic Sensors and Systems; Artech House: London, UK, 2018; ISBN 9781630812430.

193. Villani, C.; Balsamo, D.; Brunelli, D.; Benini, L. Ultra-Low Power Sensor for Autonomous Non-Invasive Voltage Measurement in IoT Solutions for Energy Efficiency. Smart Sens. Actuators MEMS VII Cyber Phys. Syst. 2015, 9517, 95172I. [CrossRef]

194. Kassal, P.; Steinberg, I.M.; Steinberg, M.D. Wireless Smart Tag with Potentiometric Input for Ultra Low-Power Chemical Sensing. Sens. Actuators B Chem. 2013, 184, 254-259. [CrossRef]

195. Laubhan, K.; Talaat, K.; Riehl, S.; Aman, M.S.; Abdelgawad, A.; Yelamarthi, K. A Low-Power IoT Framework: From Sensors to the Cloud. In Proceedings of the 2016 IEEE International Conference on Electro Information Technology (EIT), Grand Forks, ND, USA, 19-21 May 2016; pp. 648-652. [CrossRef]

196. Kuo, Y.W.; Li, C.L. Design of Long Range Low Power Sensor Node for the Last Mile of IoT. In Proceedings of the 2016 IEEE International Conference on Consumer Electronics-Taiwan (ICCE-TW), Nantou, Taiwan, 27-29 May 2016; pp. 15-16. [CrossRef]

197. Akella Kamakshi, D.; Shrivastava, A.; Calhoun, B.H. A 0.2 V, 23 NW CMOS Temperature Sensor for Ultra-Low-Power IoT Applications. J. Low Power Electron. Appl. 2016, 6, 10. [CrossRef]

198. Garulli, N.; Boni, A.; Caselli, M.; Magnanini, A.; Tonelli, M. A Low Power Temperature Sensor for IOT Applications in CMOS 65nm Technology. In Proceedings of the 2017 IEEE 7th International Conference on Consumer Electronics-Berlin (ICCE-Berlin), Berlin, Germany, 3-6 September 2017; pp. 92-96. [CrossRef]

199. Banerjee, A.; Ghosh, T.; Likhite, R.; Hasan, N.; Kim, H.; Mastrangelo, C.H. Electrical Detection of Proteins Using Batch-Fabricated Vertical Metal Nanogap Break-Junctions. In Proceedings of the 20th International Conference on Miniaturized Systems for Chemistry and Life Sciences, MicroTAS 2016, Dublin, Ireland, 9-13 October 2016; pp. 1230-1231.

200. Banerjee, A.; Farhoudi, N.; Ghosh, C.; Mastrangelo, C.H.; Kim, H.; Broadbent, S.J.; Looper, R. Picowatt Gas Sensing and Resistance Switching in Tunneling Nano-Gap Electrodes. In Proceedings of the 2016 IEEE SENSORS, Orlando, FL, USA, 30 October-3 November 2016. [CrossRef]

201. Ghosh, C.; Khan, S.H.; Broadbent, S.J.; Hsieh, H.C.; Noh, S.; Banerjee, A.; Farhoudi, N.; Mastrangelo, C.H.; Looper, R.; Kim, H. Nano-Gap Vapor Sensor. In Proceedings of the 2017 IEEE SENSORS, Glasgow, UK, 29 October-1 November 2017 ; pp. 1-3.

202. Khan, S.H.; Banerjee, A.; Jung, Y.J.; Hsieh, H.C.; Wu, T.; Mastrangelo, C.H.; Kim, H. Ultra-Low-Power Chemical Sensor Node. In Proceedings of the GOMACTech 2018, Miami, FL, USA, 9 January 2018; pp. 6-9.

203. Khan, S.H.; Banerjee, A.; Broadbent, S.; Kairy, P.D.; Kim, K.H.; Mastrangelo, C.H.; Looper, R.; Kim, H. Molecular Length Based Target Identification Using a Nano-Gap Sensor. In Proceedings of the 2019 IEEE 32nd International Conference on Micro Electro Mechanical Systems (MEMS), Seoul, Korea, 27-31 January 2019; pp. 460-463.

204. Khan, S.H.; Banerjee, A.; Broadbent, S.; Bulbul, A.; Simmons, M.C.; Kim, K.H.; Mastrangelo, C.H.; Looper, R.; Kim, H. StatisticsBased Gas Sensor. In Proceedings of the 2019 IEEE 32nd International Conference on Micro Electro Mechanical Systems (MEMS), Seoul, Korea, 27-31 January 2019; pp. 137-140.

205. Banerjee, A.; Khan, S.-U.H.; Broadbent, S.; Likhite, R.; Looper, R.; Kim, H.; Mastrangelo, C.H. Batch-Fabricated $\alpha$-Si Assisted Nanogap Tunneling Junctions. Nanomaterials 2019, 9, 727. [CrossRef] [PubMed]

206. Khan, S.H.; Banerjee, A.; Kim, K.H.; Salvant, J.; Looper, R.; Mastrangelo, C.H.; Kim, H. Threshold Point Modulation of a Wake-Up Nano-Gap Gas Sensor. In Proceedings of the 2020 IEEE 33rd International Conference on Micro Electro Mechanical Systems (MEMS), Vancouver, BC, Canada, 18-22 January 2020; pp. 733-736.

207. Truong, S.K.M.; Kim, K.H.; Khan, S.H.; Salvant, J.; Banerjee, A.; Looper, R.; Mastrangelo, C.H.; Kim, H. Demonstration of $\$ 155.1 \backslash \backslash \mathrm{mu} \backslash$ mathrm $\{\mathrm{W}\}$ \$ Wake-Up Gas Sensor Node Toward 8 Month Lifetime. In Proceedings of the 2020 IEEE 33rd International Conference on Micro Electro Mechanical Systems (MEMS), Vancouver, BC, Canada, 18-22 January 2020; pp. 622-625.

208. Pandey, S.S.; Banerjee, N.; Banerjee, A.; Hasan, N.; Kim, H.; Mastrangelo, C.H. High-Sensitivity Parametrically Amplified Chemo-Mechanical Vapor Sensors. In Proceedings of the 2015 IEEE SENSORS, Busan, Korea, 1-4 November 2015; pp. 1-4. 
209. Likhite, R.; Pandey, S.S.; Banerjee, A.; Kim, H.; Mastrangelo, C.H. Amplified Chemomechanical Comb Gas Sensor. In Proceedings of the 2016 IEEE SENSORS, Orlando, FL, USA, 30 October-3 November 2016. [CrossRef]

210. Likhite, R.; Banerjee, A.; Kim, H.; Mastrangelo, C.H. Self-Leveling Micromechanical Gas Sensors. In Proceedings of the 2018 IEEE SENSORS, New Delhi, India, 28-31 October 2018; pp. 1-4.

211. Likhite, R.; Banerjee, A.; Majumder, A.; Karkhanis, M.; Kim, H.; Mastrangelo, C.H. Parametrically Amplified Low-Power MEMS Capacitive Humidity Sensor. Sensors 2019, 19, 3954. [CrossRef] [PubMed]

212. Banerjee, A.; Likhite, R.; Kim, H.; Mastrangelo, C. An Ultra-Low Power Highly-Sensitive Vapor Sensor Based on Quantum Tunneling. In Proceedings of the The 23rd International Conference onMiniaturized Systems for Chemistry and Life Sciences MicroTAS 2019, Basel, Switzerland, 27-31 October 2019; pp. 1330-1331.

213. Banerjee, A.; Likhite, R.; Kim, H.; Mastrangelo, C.H. Quantum Tunneling Hygrometer with Temperature Stabilized Nanometer Gap. Sci. Rep. 2020, 10, 4440. [CrossRef]

214. Likhite, R.; Banerjee, A.; Majumder, A.; Karkhanis, M.; Kim, H.; Mastrangelo, C.H. VOC Sensing Using Batch-Fabricated Temperature Compensated Self-Leveling Microstructures. Sens. Actuators B Chem. 2020, 311, 127817. [CrossRef]

215. Beach, C.; Krachunov, S.; Pope, J.; Fafoutis, X.; Piechocki, R.J.; Craddock, I.; Casson, A.J. An Ultra Low Power Personalizable Wrist Worn ECG Monitor Integrated with IoT Infrastructure. IEEE Access 2018, 6, 44010-44021. [CrossRef]

216. Chen, X.; Rhee, W.; Wang, Z. Low Power Sensor Design for IoT and Mobile Healthcare Applications. China Commun. 2015, 12, 42-54. [CrossRef]

217. Gatouillat, A.; Massot, B.; Badr, Y.; Sejdic, E.; Gehin, C. Evaluation of a Real-Time Low-Power Cardiorespiratory Sensor for the IoT. In Proceedings of the 2018 40th Annual International Conference of the IEEE Engineering in Medicine and Biology Society (EMBC), Honolulu, HI, USA, 18-21 July 2018; pp. 5382-5385. [CrossRef]

218. Medu, H. Available online: http://www.ecnmag.com/article/2018/11/low-power-memory-iot-wearables-and-portablemedical-devices (accessed on 1 January 2021).

219. Hayashikoshi, M.; Noda, H.; Kawai, H.; Murai, Y.; Otani, S.; Nii, K.; Matsuda, Y.; Kondo, H. Low-Power Multi-Sensor System with Power Management and Nonvolatile Memory Access Control for IoT Applications. IEEE Trans. Multi Scale Comput. Syst. 2018, 4, 784-792. [CrossRef]

220. Banerjee, N.; Banerjee, A.; Hasan, N.; Pandey, S.S.; Gogoi, B.P.; Mastrangelo, C.H. A Monolithically Integrated Multisensor Platform. IEEE Sens. J. 2016, 16. [CrossRef]

221. Tresanchez, M.; Pujol, A.; Pallejà, T.; Martínez, D.; Clotet, E.; Palacín, J. A Proposal of Low-Cost and Low-Power Embedded Wireless Image Sensor Node for IoT Applications. Procedia Comput. Sci. 2018, 134, 99-106. [CrossRef]

222. Fayyazi, A.; Ansari, M.; Kamal, M.; Afzali-Kusha, A.; Pedram, M. An Ultra Low-Power Memristive Neuromorphic Circuit for Internet of Things Smart Sensors. IEEE Internet Things J. 2018, 5, 1011-1022. [CrossRef]

223. Ma, S.; Liu, Q.; Sheu, P.C.Y. Foglight: Visible Light-Enabled Indoor Localization System for Low-Power IoT Devices. IEEE Internet Things J. 2018, 5, 175-185. [CrossRef]

224. Apple Is the Last Major Smart Home Provider to Join Thread Group. Available online: https://www.fiercewireless.com/tech/ apple-last-major-smart-home-provider-to-join-thread-group (accessed on 1 December 2020).

225. Google Details Its Vision for the IoT. Available online: https://www.networkworld.com/article/3021820/google-ubiquitysummit-iot.html (accessed on 1 December 2020).

226. Amazon Intros "Sidewalk" Protocol for Low-Power IoT Networks. Available online: https://www.lightreading.com/iot/m2mplatforms/amazon-intros-sidewalk-protocol-for-low-power-iot-networks/d/d-id/754392 (accessed on 1 December 2020).

227. IoT Market Research Reports: Technology, Application, M2M \& Semiconductor Wireless Sensor Internet of Things 2014 Analysis and 2020 Forecasts. Available online: https://go-gale-com.ezproxy.lib.utah.edu/ps/i.do?id=GALE\%7CA369414466\&v=2.1\&u= marriottlibrary\&it=r\&p=AONE\&sw=w (accessed on 1 December 2020).

228. Semtech LoRa Technology Used by Trimble for IoT Water Monitoring Sensor Series. GlobeNewswire 2016: GlobeNewswire. 8 December 2016. Available online: https:/ / www.globenewswire.com/news-release/2016/12/08/896112/0/en/Semtech-LoRaTechnology-Used-by-Trimble-for-IoT-Water-Monitoring-Sensor-Series.html. (accessed on 1 December 2020).

229. New BluetoothA®Low Energy and Energy Harvesting Sensor Shields Further Extend the Capabilities of ON Semiconductor's IoT Development Kit. Ultra-Low Power Connectivity and Battery-Free Sensing Solutions Enable Development of Novel IoT Use. M2 Pressw. Available online: https:/ / www.electronicsmedia.info/2017/11/30/new-bluetooth-low-energy-energy-harvestingsensor-shields-extend-capabilities-semiconductors-iot-development-kit/ (accessed on 1 December 2020).

230. Reducing Power failures with netl's low-cost electrical asset monitoring sensor technology. States News Service 2018: States News Service. 22 January 2018. Available online: https:/ / www.engineering.pitt.edu/News/2018/NETL-Chen-Sensor-Tech/ (accessed on 1 December 2020).

231. Industry Veteran Jeremy Jaech Lands $\$ 1.5$ Million from Madrona Venture Group and Radar Partners for Innovative Low Power Sensor Technology; Founds SNUPI Technologies. PR Newswire 2012: PR Newswire. 11 December 2012. Available online: https:/ / www.prnewswire.com/news-releases/industry-veteran-jeremy-jaech-lands-15-million-from-madrona-venturegroup-and-radar-partners-for-innovative-low-power-sensor-technology-founds-snupi-technologies-183008391.html (accessed on 1 December 2020). 
232. Future Electronics Features RSL10 Solar Cell Multi-Sensor Platform from ON Semiconductor. PR.Com (Press Releases) 2019: PR.Com (Press Releases). 5 October 2019. Available online: https://www.freepressreleasedb.com/pr/Future-ElectronicsFeatures-RSL10-Solar-Cell-Multi-Sensor-Platform-from-ON-Semiconductor-PR126273/ (accessed on 1 December 2020).

233. Socionext Unveils New, Next-Generation Radar Sensors for IoT, Smart Home, and Other Applications. PR Newswire 2019: PR Newswire. 3 October 2019. Available online: https://www.rfglobalnet.com/doc/socionext-unveils-next-generation-radarsensors-for-iot-smart-home-and-other-applications-0001 (accessed on 1 December 2020).

234. Sales 13 IoT Statistics Defining the Future of Internet of Things. Available online: https://www.newgenapps.com/blog/iotstatistics-internet-of-things-future-research-data (accessed on 1 December 2020).

235. Goswami, P. Advanced Materials and Techniques for Biosensors and Bioanalytical Applications, 1st ed.; Goswami, P., Ed.; CRC Press: Boca Raton, FL, USA, 2020; ISBN 9781003083856.

236. Cui, F.; Yue, Y.; Zhang, Y.; Zhang, Z.; Zhou, H.S. Advancing Biosensors with Machine Learning. ACS Sens. 2020, 5, 3346-3364. [CrossRef]

237. Guselnikova, O.; Trelin, A.; Skvortsova, A.; Ulbrich, P.; Postnikov, P.; Pershina, A.; Sykora, D.; Svorcik, V.; Lyutakov, O. Label-Free Surface-Enhanced Raman Spectroscopy with Artificial Neural Network Technique for Recognition Photoinduced DNA Damage. Biosens. Bioelectron. 2019, 145, 111718. [CrossRef] [PubMed]

238. Erzina, M.; Trelin, A.; Guselnikova, O.; Dvorankova, B.; Strnadova, K.; Perminova, A.; Ulbrich, P.; Mares, D.; Jerabek, V.; Elashnikov, R.; et al. Precise Cancer Detection via the Combination of Functionalized SERS Surfaces and Convolutional Neural Network with Independent Inputs. Sens. Actuators B Chem. 2020, 308, 127660. [CrossRef]

239. Thrift, W.J.; Ragan, R. Quantification of Analyte Concentration in the Single Molecule Regime Using Convolutional Neural Networks. Anal. Chem. 2019, 91, 13337-13342. [CrossRef]

240. Lu, W.; Chen, X.; Wang, L.; Li, H.; Fu, Y.V. Combination of an Artificial Intelligence Approach and Laser Tweezers Raman Spectroscopy for Microbial Identification. Anal. Chem. 2020, 92, 6288-6296. [CrossRef] [PubMed]

241. Pandit, S.; Banerjee, T.; Srivastava, I.; Nie, S.; Pan, D. Machine Learning-Assisted Array-Based Biomolecular Sensing Using Surface-Functionalized Carbon Dots. ACS Sens. 2019, 4, 2730-2737. [CrossRef]

242. Solmaz, M.E.; Mutlu, A.Y.; Alankus, G.; Kılıç, V.; Bayram, A.; Horzum, N. Quantifying Colorimetric Tests Using a Smartphone App Based on Machine Learning Classifiers. Sens. Actuators B Chem. 2018, 255, 1967-1973. [CrossRef]

243. Gunda, N.S.K.; Gautam, S.H.; Mitra, S.K. Editors' Choice-Artificial Intelligence Based Mobile Application for Water Quality Monitoring. J. Electrochem. Soc. 2019, 166, B3031-B3035. [CrossRef]

244. Kim, H.; Awofeso, O.; Choi, S.; Jung, Y.; Bae, E. Colorimetric Analysis of Saliva-Alcohol Test Strips by Smartphone-Based Instruments Using Machine-Learning Algorithms. Appl. Opt. 2017, 56, 84. [CrossRef]

245. Ballard, Z.S.; Joung, H.-A.; Goncharov, A.; Liang, J.; Nugroho, K.; Di Carlo, D.; Garner, O.B.; Ozcan, A. Deep Learning-Enabled Point-of-Care Sensing Using Multiplexed Paper-Based Sensors. NPJ Digit. Med. 2020, 3, 66. [CrossRef] [PubMed]

246. Luo, R.; Ma, G.; Bi, S.; Duan, Q.; Chen, J.; Feng, Y.; Liu, F.; Lee, J. Machine Learning for Total Organic Carbon Analysis of Environmental Water Samples Using High-Throughput Colorimetric Sensors. Analyst 2020, 145, 2197-2203. [CrossRef]

247. Gonzalez-Navarro, F.; Stilianova-Stoytcheva, M.; Renteria-Gutierrez, L.; Belanche-Muñoz, L.; Flores-Rios, B.; Ibarra-Esquer, J. Glucose Oxidase Biosensor Modeling and Predictors Optimization by Machine Learning Methods. Sensors 2016, 16, 1483. [CrossRef]

248. Ali, S.; Hassan, A.; Hassan, G.; Eun, C.-H.; Bae, J.; Lee, C.H.; Kim, I.-J. Disposable All-Printed Electronic Biosensor for Instantaneous Detection and Classification of Pathogens. Sci. Rep. 2018, 8, 5920. [CrossRef]

249. Albrecht, T.; Slabaugh, G.; Alonso, E.; Al-Arif, S.M.R. Deep Learning for Single-Molecule Science. Nanotechnology $2017,28,423001$. [CrossRef]

250. Tsutsui, M.; Yoshida, T.; Yokota, K.; Yasaki, H.; Yasui, T.; Arima, A.; Tonomura, W.; Nagashima, K.; Yanagida, T.; Kaji, N.; et al. Discriminating Single-Bacterial Shape Using Low-Aspect-Ratio Pores. Sci. Rep. 2017, 7, 17371. [CrossRef] [PubMed]

251. Zeng, Z.; Huang, Z.; Leng, K.; Han, W.; Niu, H.; Yu, Y.; Ling, Q.; Liu, J.; Wu, Z.; Zang, J. Nonintrusive Monitoring of Mental Fatigue Status Using Epidermal Electronic Systems and Machine-Learning Algorithms. ACS Sens. 2020, 5, 1305-1313. [CrossRef]

252. Jeong, H.; Rogers, J.A.; Xu, S. Continuous On-Body Sensing for the COVID-19 Pandemic: Gaps and Opportunities. Sci. Adv. 2020, 6, eabd4794. [CrossRef] [PubMed]

253. Tatarko, M.; Muckley, E.S.; Subjakova, V.; Goswami, M.; Sumpter, B.G.; Hianik, T.; Ivanov, I.N. Machine Learning Enabled Acoustic Detection of Sub-Nanomolar Concentration of Trypsin and Plasmin in Solution. Sens. Actuators B Chem. 2018, 272, 282-288. [CrossRef]

254. Adak, M.F.; Lieberzeit, P.; Jarujamrus, P.; Yumusak, N. Classification of Alcohols Obtained by QCM Sensors with Different Characteristics Using ABC Based Neural Network. Eng. Sci. Technol. Int. J. 2020, 23, 463-469. [CrossRef]

255. Yan, W.; Wang, K.; Xu, H.; Huo, X.; Jin, Q.; Cui, D. Machine Learning Approach to Enhance the Performance of MNP-Labeled Lateral Flow Immunoassay. Nano-Micro Lett. 2019, 11, 7. [CrossRef] 